\title{
Controlled Nanoconfinement of Polyimide Networks in Mesoporous $\gamma$ - Alumina Membranes for Molecular Separation of Organic Dyes
}

Nikos Kyriakou, ${ }^{a}$ Louis Winnubst, ${ }^{\text {a, }}$ Martin Drobek ${ }^{\mathrm{b}}$ Sissi de Beer, ${ }^{\mathrm{c}}$ Arian Nijmeijer, ${ }^{\mathrm{a}}$ and Marie-Alix Pizzoccaro-Zilamy,

${ }^{a}$ Inorganic Membranes, MESA+ Institute for Nanotechnology, University of Twente, $7500 \mathrm{AE}$ Enschede, The Netherlands

${ }^{\mathrm{b}}$ Institut Européen des Membranes, UMR5635, CNRS-UM-ENSCM, Université de Montpellier (CC047), Place Eugène Bataillon, 34095 Montpellier Cedex 5, France

${ }^{\mathrm{c}}$ Sustainable Polymer Chemistry Group, Department of Molecules \& Materials, MESA+ Institute for Nanotechnology, University of Twente, 7500 AE Enschede, The Netherlands

Corresponding authors' email address: a.j.a.winnubst@utwente.nl, m.d.pizzoccaro@utwente.nl

1. Materials and methods used in this study.

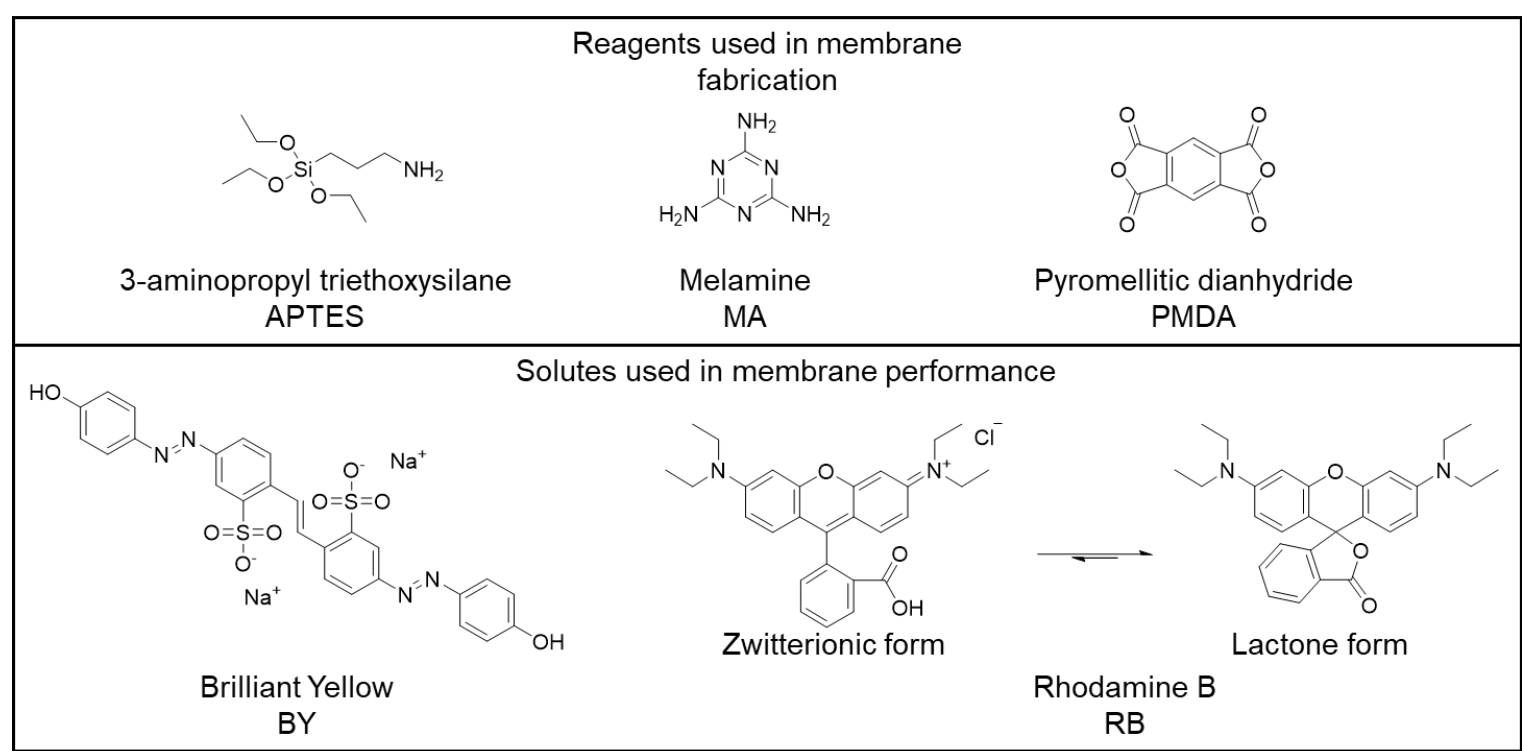

Figure S1: Chemicals used throughout this study. The chemical structures are given as well as their abbreviations as used in the article. 
1) Pre-functionalization with APTES by CVD

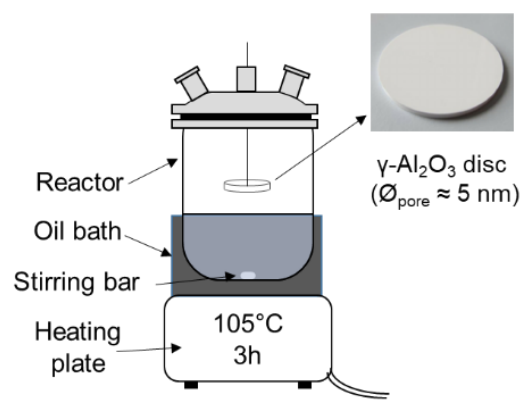

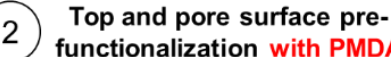

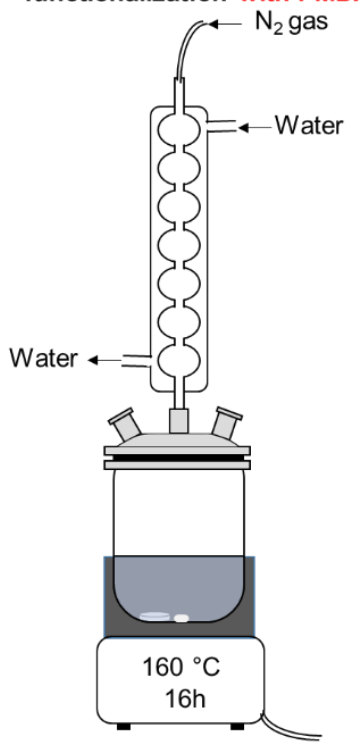

(3) In-situ polymerization with PMDA and MA

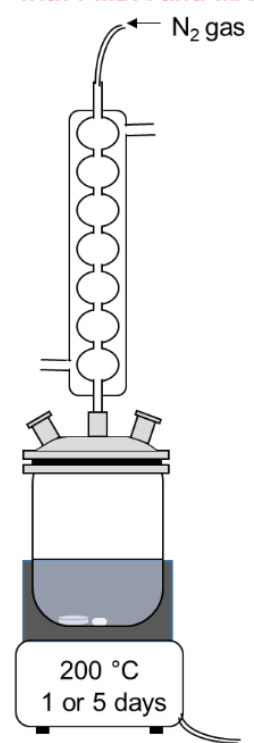

Figure S2: Schematic illustration of the equipment and procedure followed in the stepwise preparation of PI nanoconfined ceramic membranes.

2. FTIR spectra of the materials used in the preparation of the PI membranes given in the range of $4000-400 \mathrm{~cm}^{-1}$

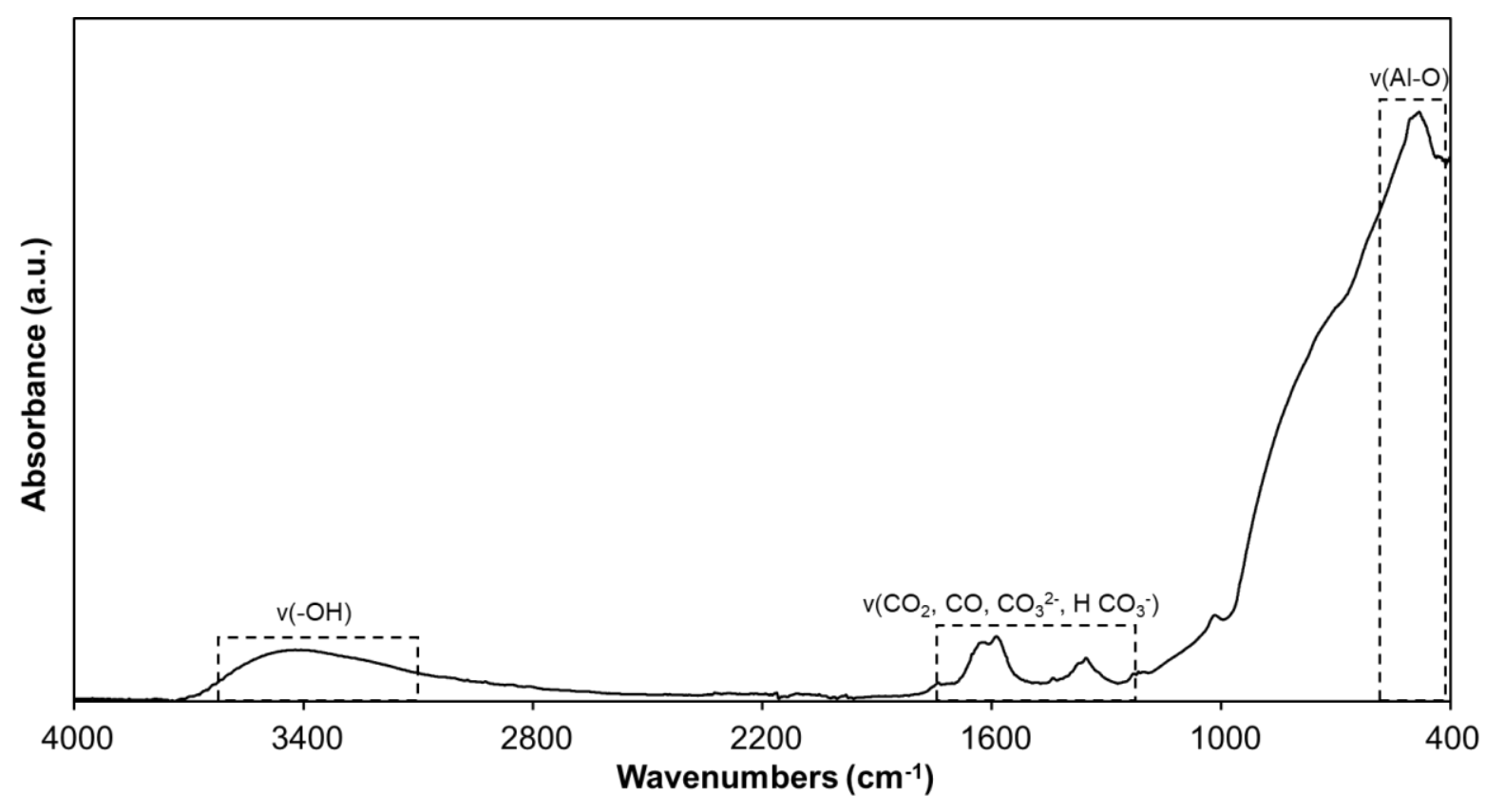

Figure S3: FTIR spectrum of pristine $\gamma$-alumina coated on $\alpha$-alumina support. ${ }^{1,2}$ 


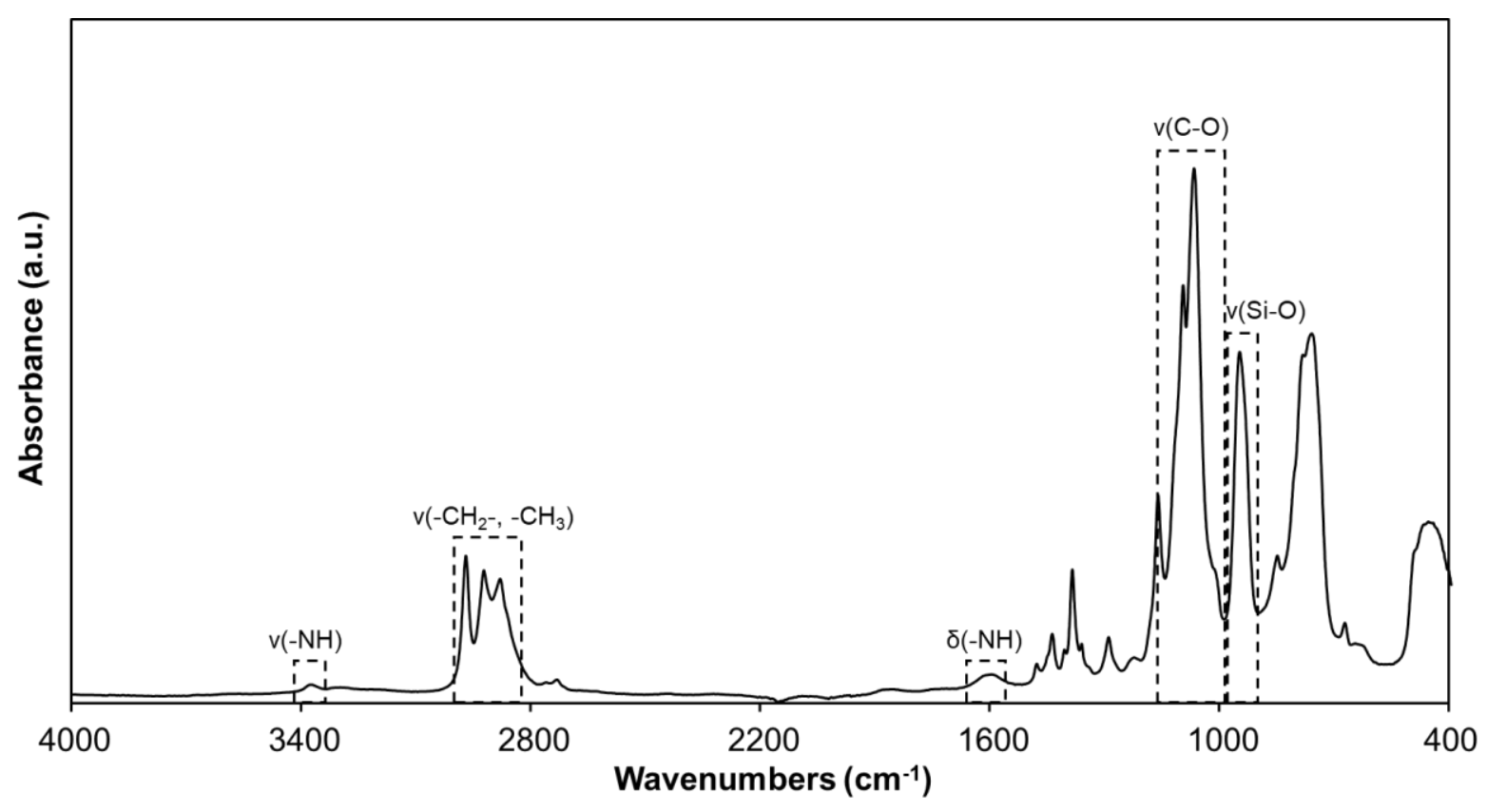

Figure S4: FTIR spectrum of pure APTES.,

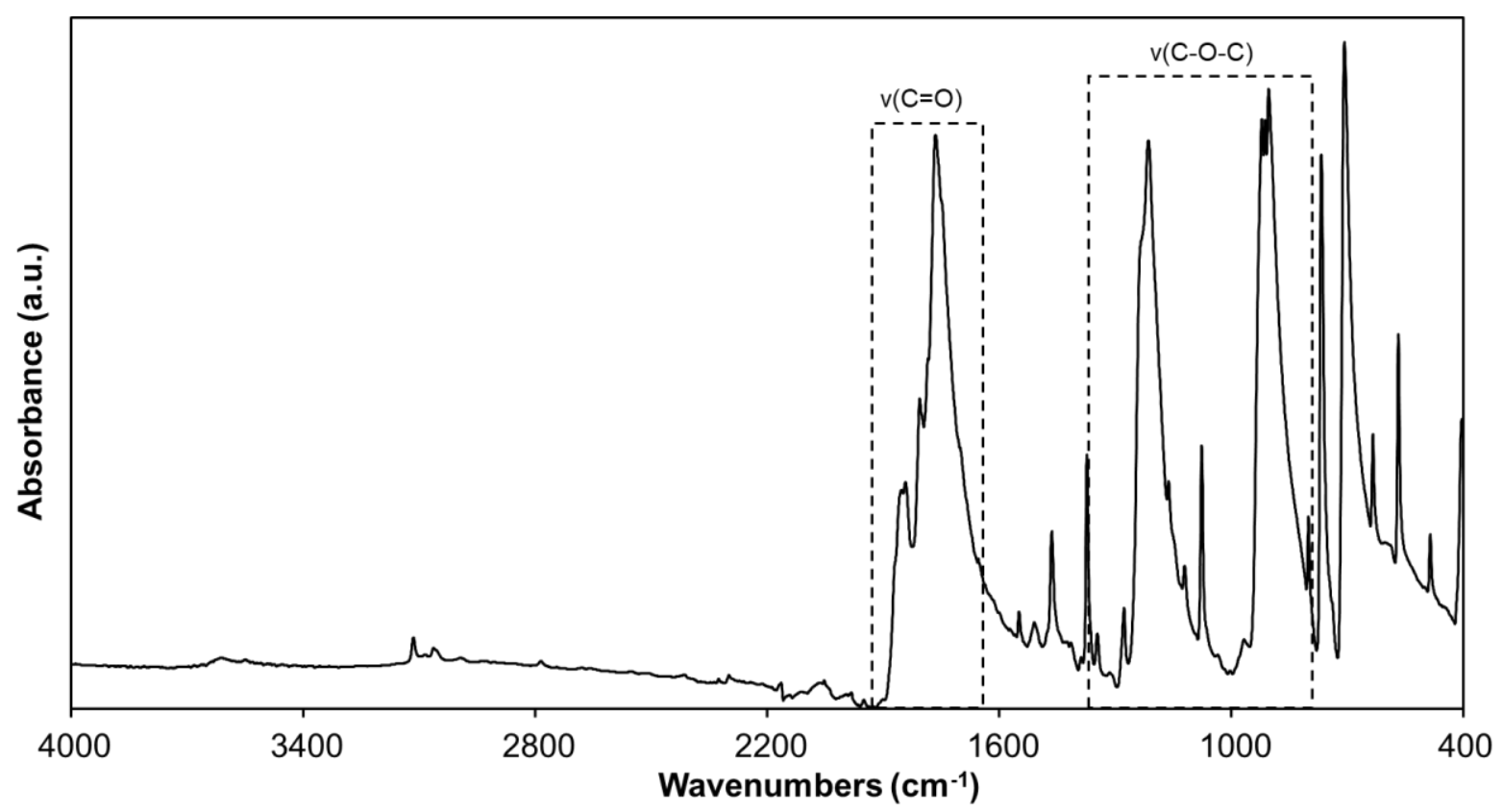

Figure S5: FTIR spectrum of PMDA. ${ }^{5}$ 


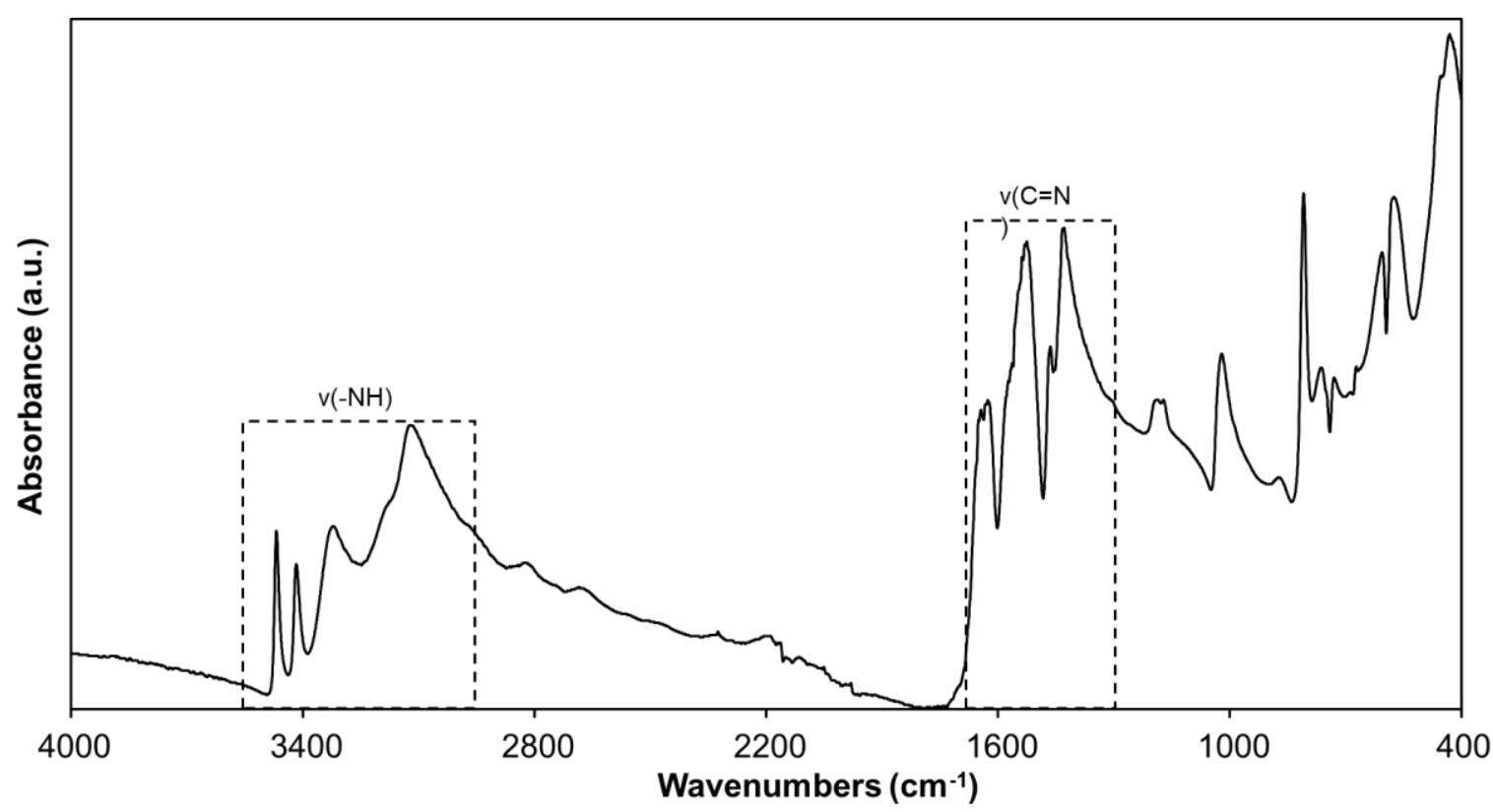

Figure S6: FTIR spectrum of MA.

3. FTIR spectra of the samples prepared given in the range of $4000-400 \mathrm{~cm}^{-2}$.

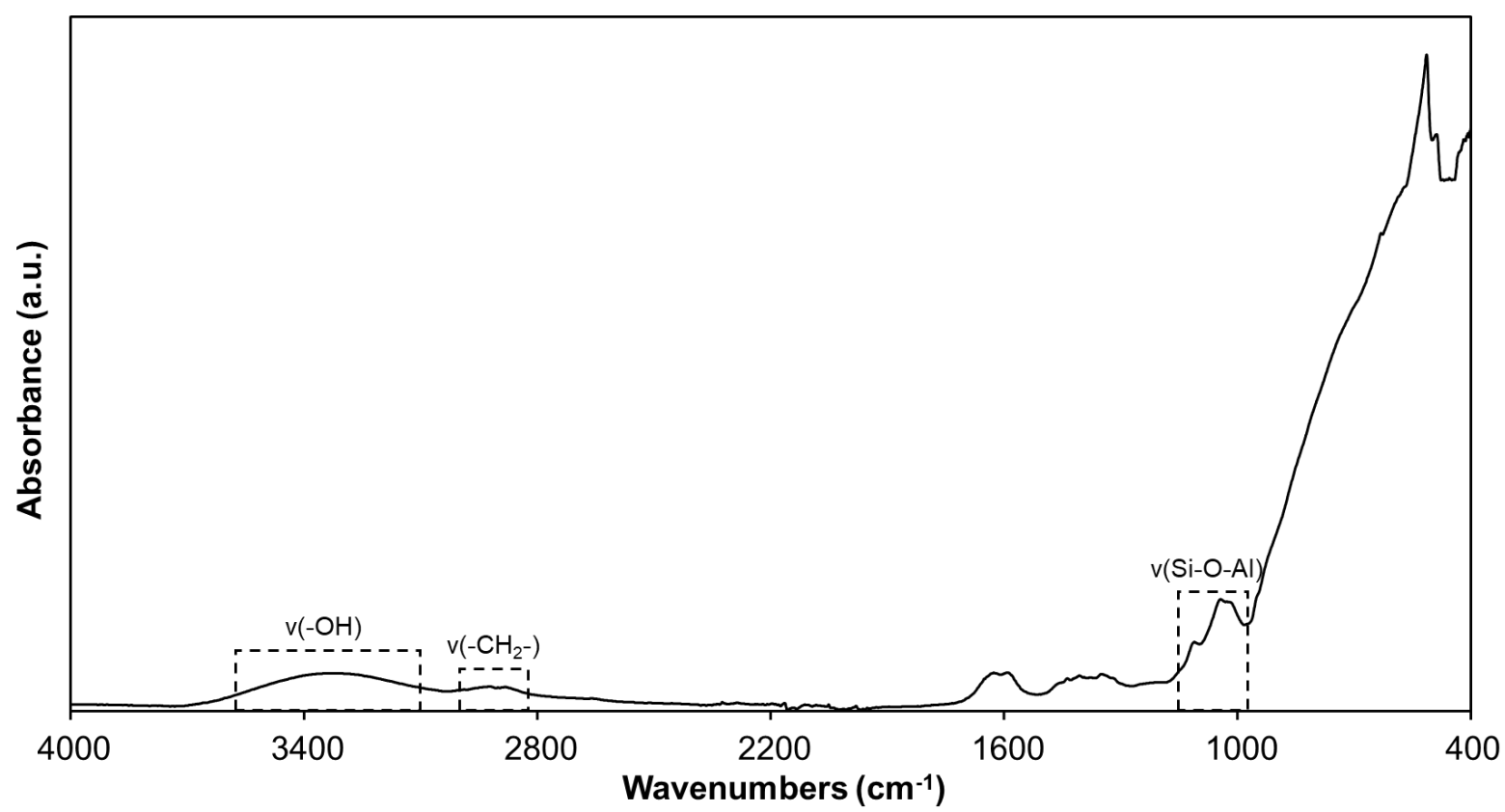

Figure S7: FTIR spectrum of sample A. 


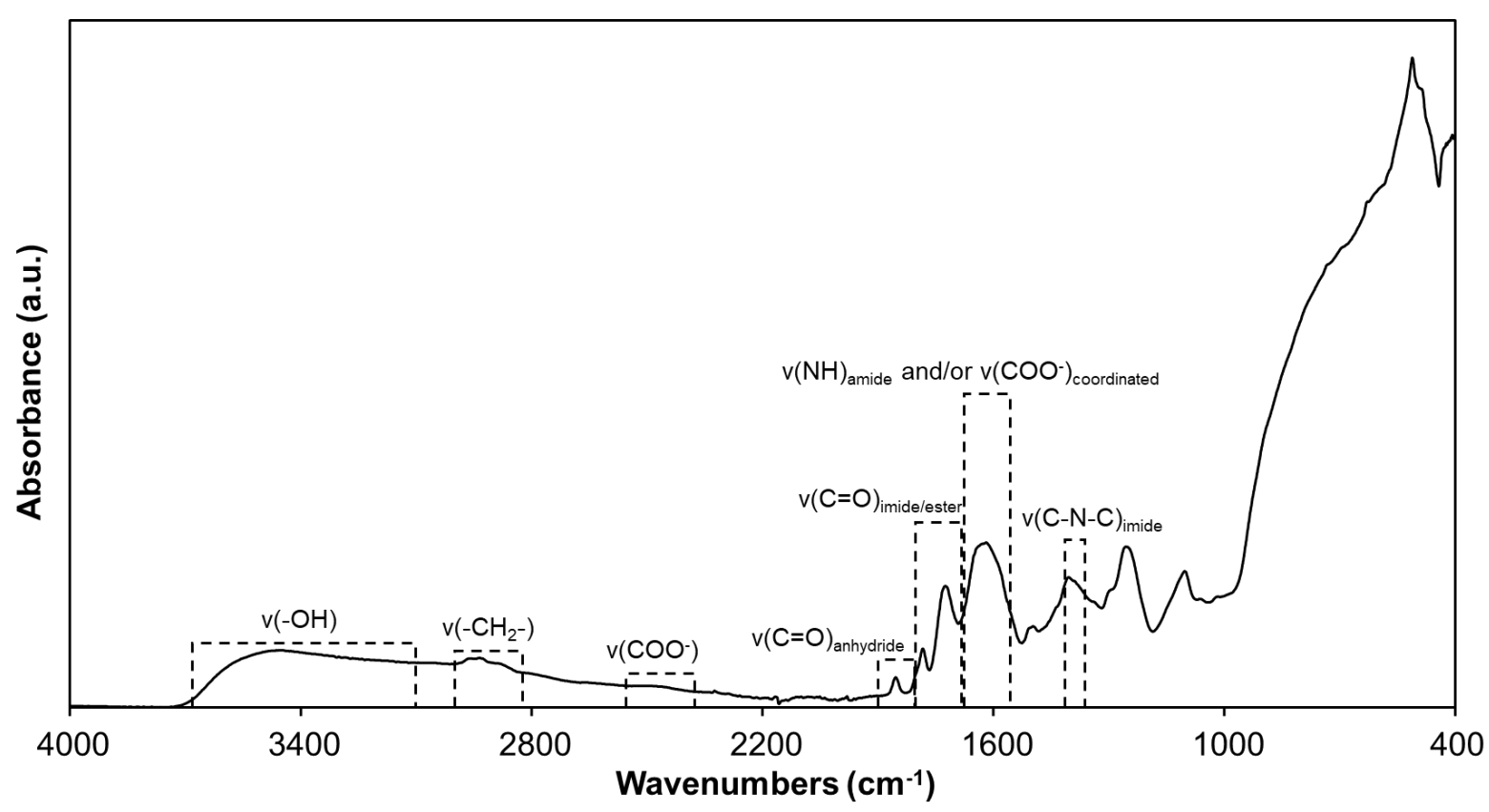

Figure S8: FTIR spectrum of sample B.

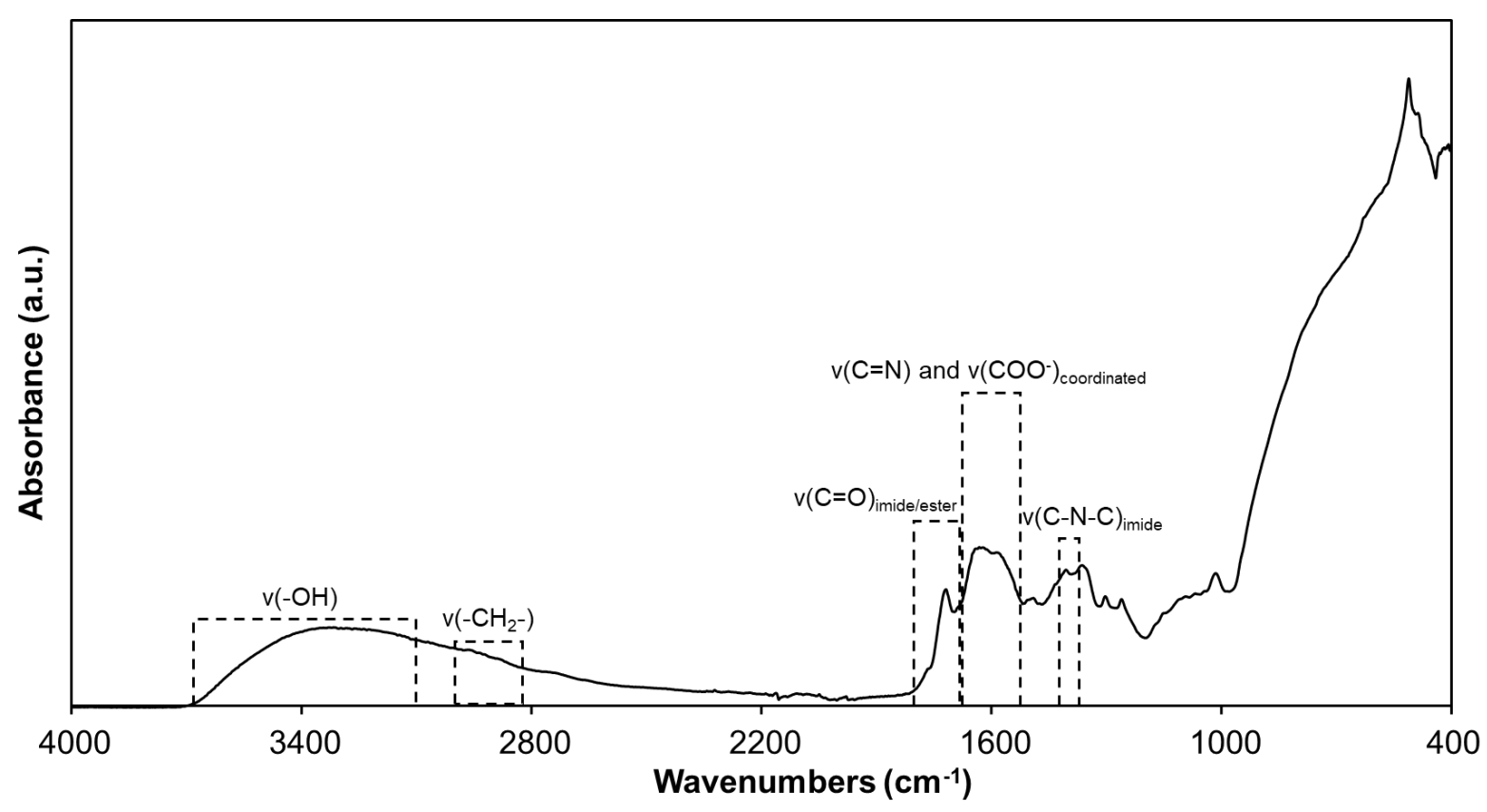

Figure S9: FTIR spectrum of sample A-1. 


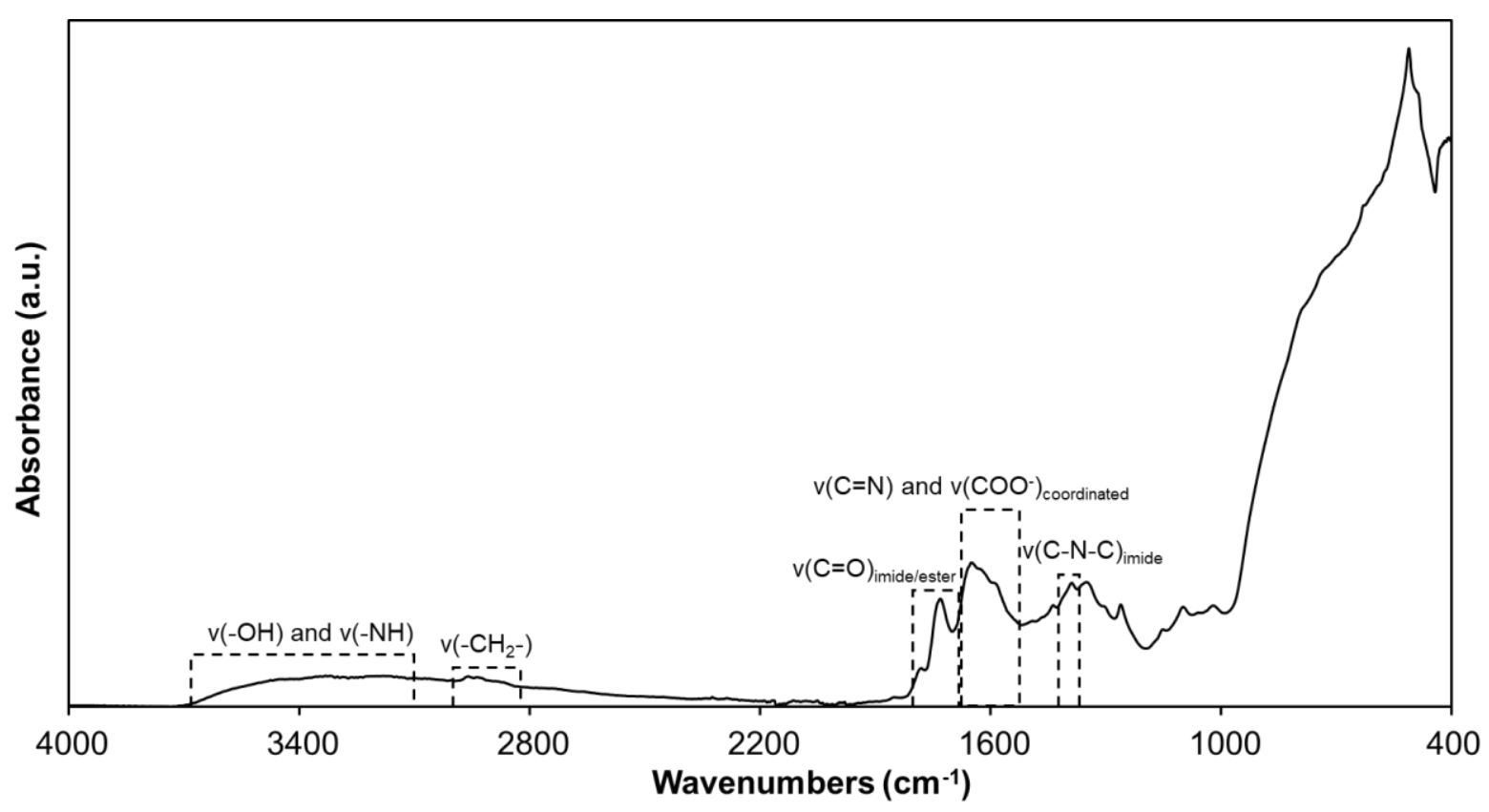

Figure S10: FTIR spectrum of sample B-1.

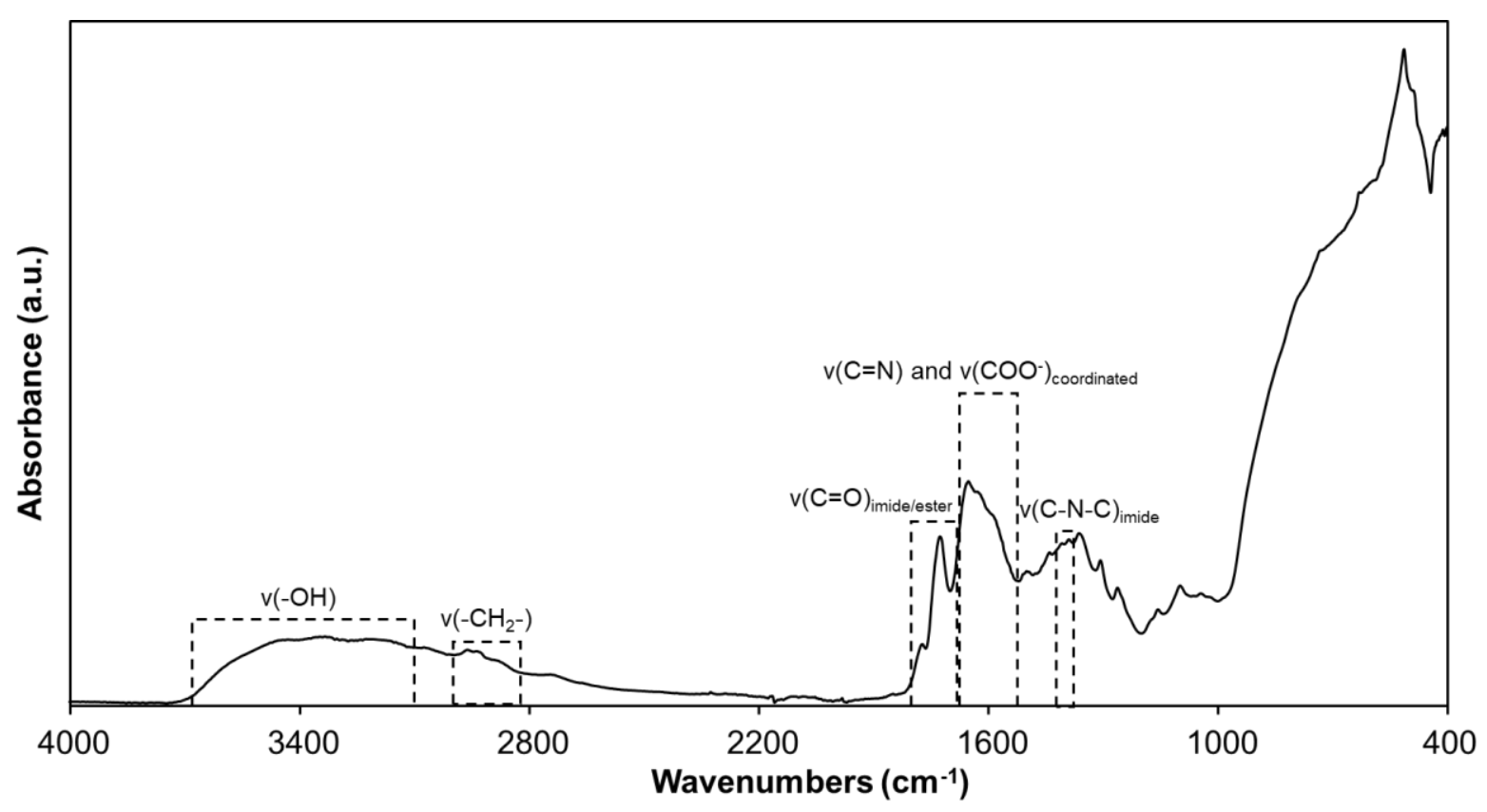

Figure S11: FTIR spectrum of sample A-5. 


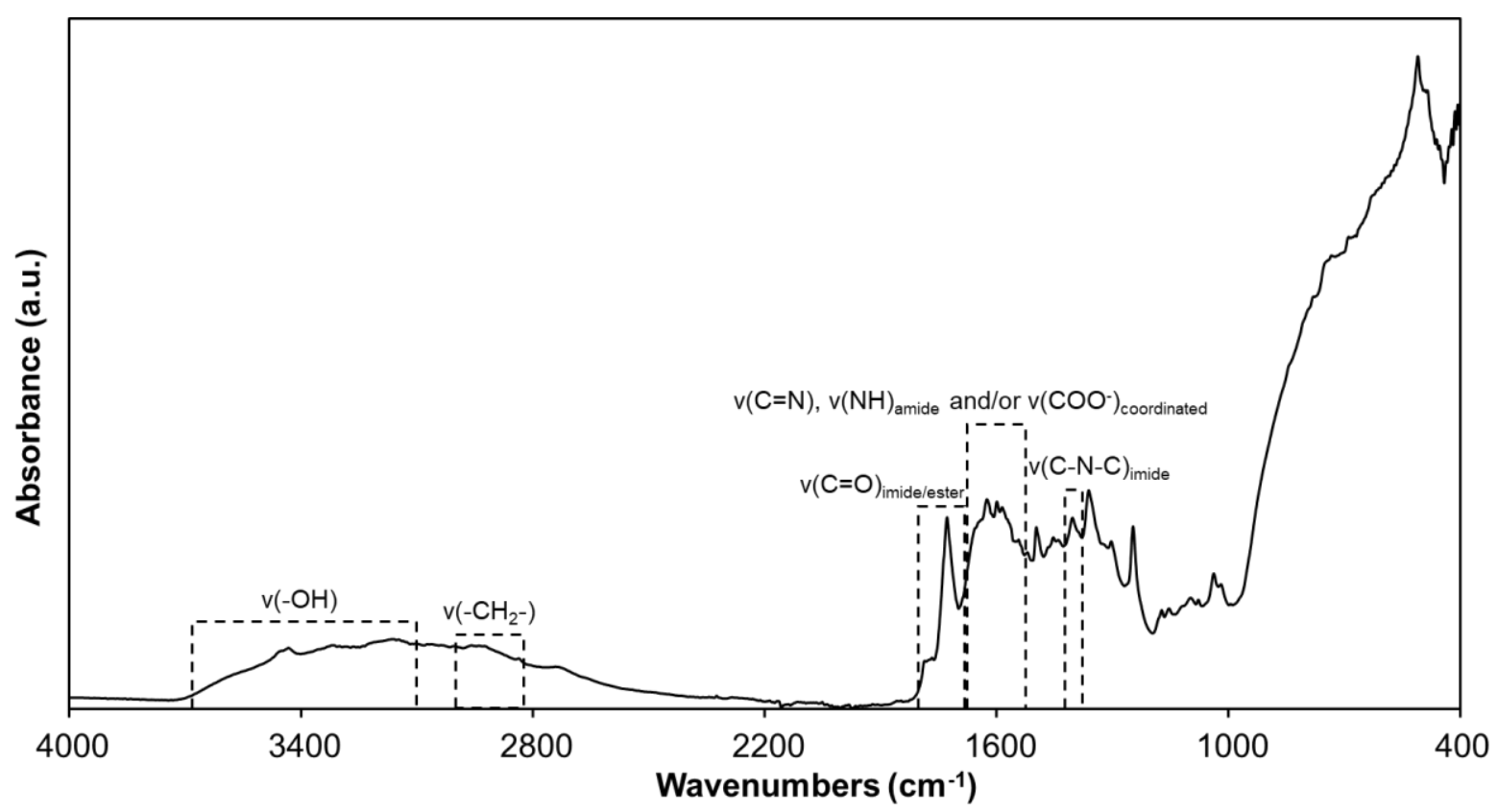

Figure S12: FTIR spectrum of sample B-5.

\section{FTIR analysis of powder samples.}

The powders were isolated as precipitates from the membrane reaction mixture. The powders shown (I-1 and I-5) were collected after the preparation of samples A-1 and A-5. However, the powders collected from B-1/5 show similar spectroscopic characteristics and therefore were not included in this analysis. The FTIR spectra of both I-1 and I-5 are shown in Figure S13 and S14, respectively. The two sharp absorption bands at 1787 and $1727 \mathrm{~cm}^{-1}$ are characteristic of the carbonyl bond of the imide group. ${ }^{6-8}$ Furthermore, the band at $1357 \mathrm{~cm}^{-1}$, attributed to the C-N-C bond of the imide group, confirms the formation of the desired imide-linked network. ${ }^{7,910}$ Additionally, the bands at 1654 and $1564 \mathrm{~cm}^{-1}$ indicate the presence of a triazine ring, a direct validation of MA in the samples. Between 3500 and $3000 \mathrm{~cm}^{-1}$ several broad absorption bands appear which can be attributed to amine terminating groups of the network. Unreacted amines are expected since amino functional groups were used in excess to the anhydride ones (dianhydride/triamine $=1.1$ ) during membrane preparation. A weak absorption band at $1857 \mathrm{~cm}^{-1}$ indicates the presence of unreacted anhydride in the sample which has either reacted partly or is physically adsorbed in the powder and due to the low solubility of PMDA is not washed off. Thus, FTIR analysis of the powders indicates the successful formation of an imide-linked network between MA and PMDA under the reaction conditions used in this work. Comparison with the four membranes, similar absorption bands are observed with the powders, but due to the considerable higher concentration of PI used and the absence of alumina during measurement, these powder FTIR-samples show a significantly higher resolution. Thus, similar chemical makeup between the powders and the PI network nanoconfined in the ceramic supports is expected. 


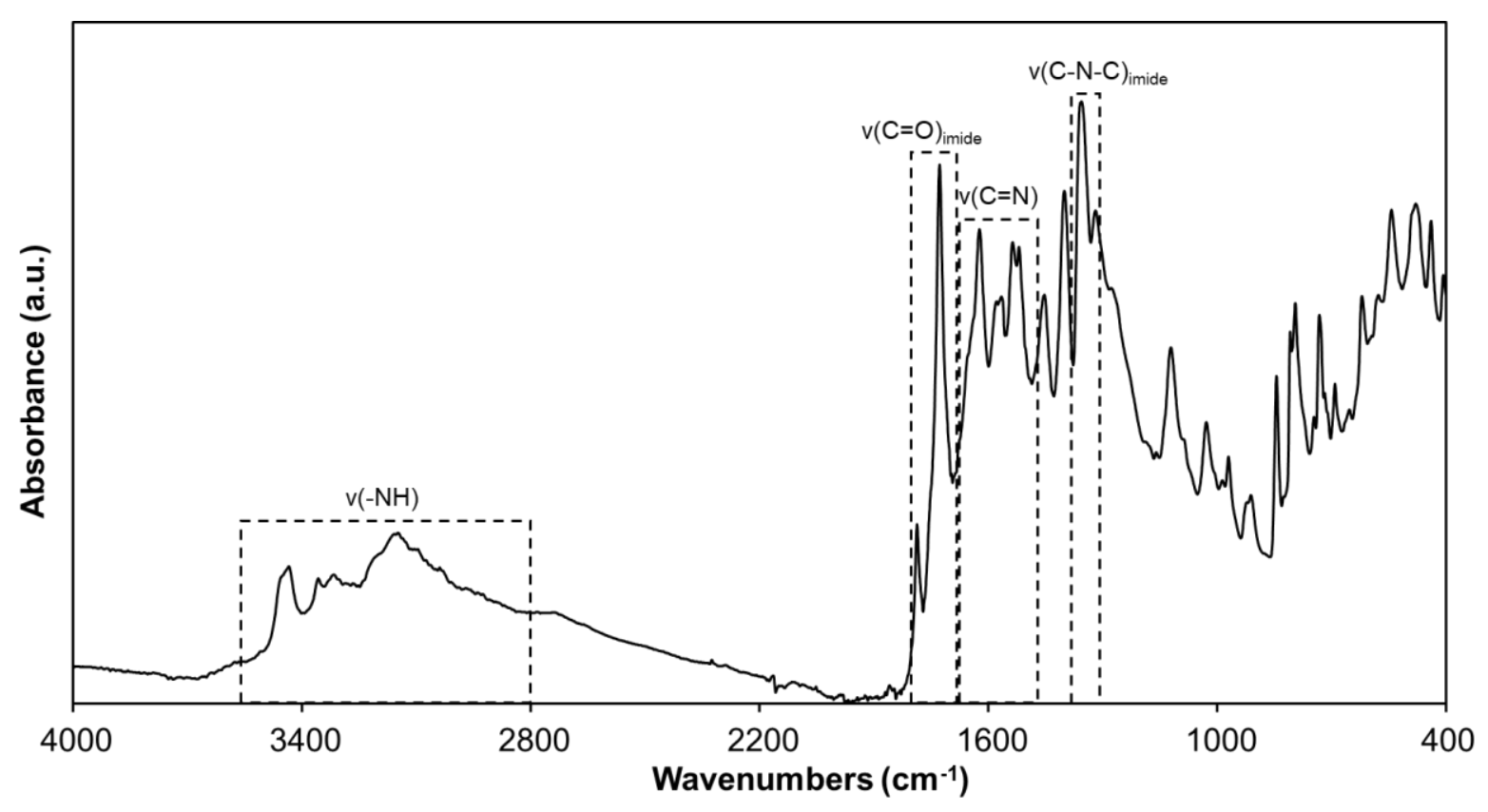

Figure S13: FTIR spectrum of sample I-1.

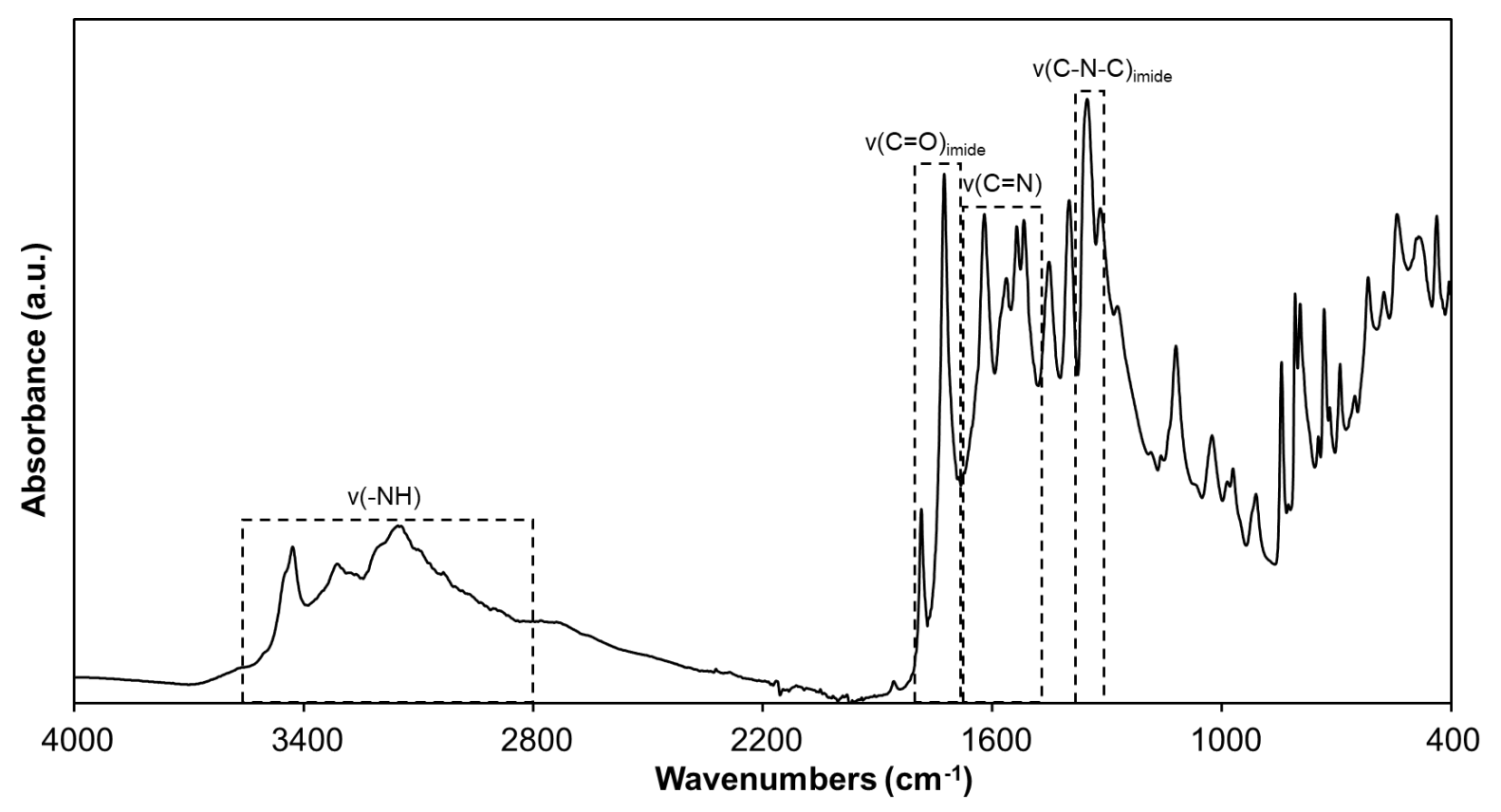

Figure S14: FTIR spectrum of sample I-5.

\section{X-ray diffraction analysis.}

An attempt was made to analyse the crystallinity of the PI network confined in the ceramic support by means of XRD. However, due to the low concentration, as compared to the support, and potentially due to the confinement of the polymer in the ceramic, no reasonable data were collected from the analysis. In Figure S15, the XRD analysis of a PI nanoconfined sample is provided and correlated with the simulated XRD diffraction pattern of $\alpha$-alumina. Evidently, the simulated and experimental results show that the PI network is not visible by means of XRD analysis. 


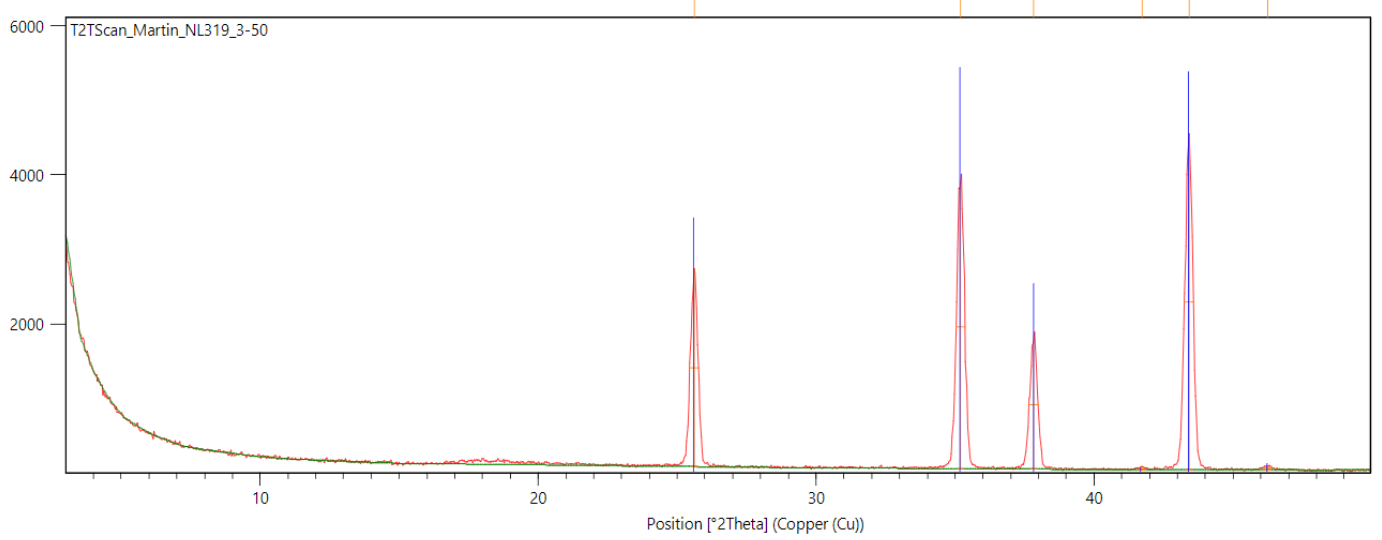

Figure S15: XRD analysis of PI nanoconfined sample (red) and correlation with molecular simulations (blue) of the $\alpha$-alumina support.

\section{Powder X-ray diffraction (XRD) analysis.}

The XRD patterns of the two PI samples are characteristic of a semicrystalline material. It can be denoted that when a reaction time of 5 days is used, the crystallinity of the material increases as evidenced from the decreasing amorphous background observed with sample I-5.

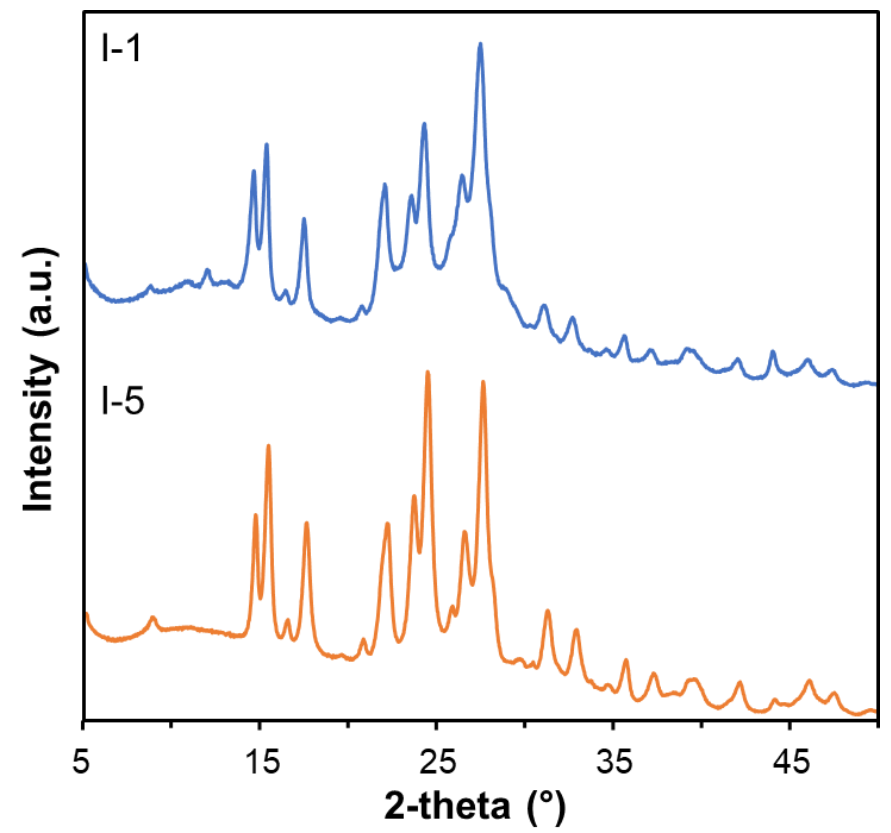

Figure S16: Powder XRD of the PI powders formed in the bulk solution during membrane fabrication for one day (I-1) and 5 days reaction (I-5).

Treatment of the PI powders at a temperature of $300^{\circ} \mathrm{C}$ results in the appearance of the distinct diffraction peak at $44^{\circ} 2 \theta$ as shown in Figure S17. This intensity of this peak is further enhanced by thermally treating the powders at $400{ }^{\circ} \mathrm{C}$ where all the other diffraction peaks of the PI matrix disappear. This can be attributed to degradation of the PI material. 


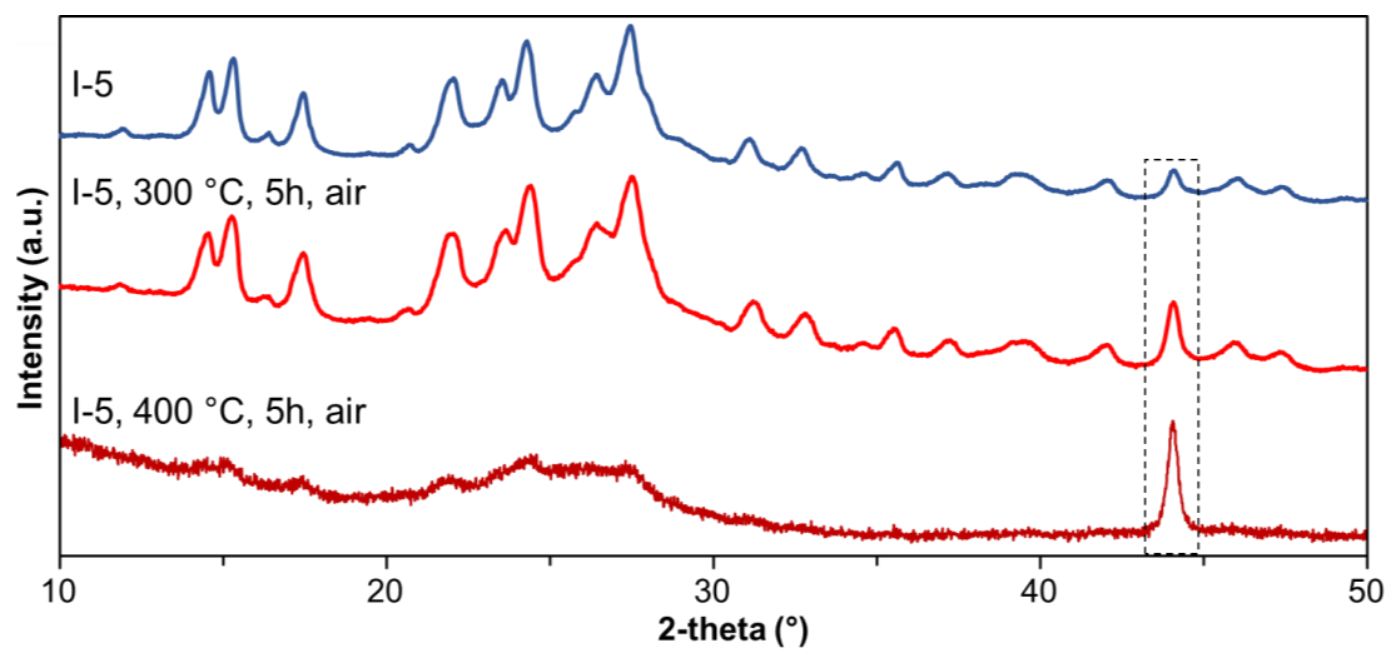

Figure S17: Powder XRD patterns of the I-5 powder after the synthesis (top), after treatment at $300{ }^{\circ} \mathrm{C}$ for $5 \mathrm{~h}$ in air (middle) and after treatment at $400{ }^{\circ} \mathrm{C}$ for $5 \mathrm{~h}$ in air (bottom).

\section{Thermogravimetric analysis (TGA) of the PI powders.}

The thermal stability of the powder samples was analysed under nitrogen atmosphere up to $1000{ }^{\circ} \mathrm{C}\left(5^{\circ} \mathrm{C} / \mathrm{min}\right)$. No weight loss is observed below $300{ }^{\circ} \mathrm{C}$ for both PI powders. The I-5 sample shows better thermal stability up to approximately $400{ }^{\circ} \mathrm{C}$. These results are corroborated by the powder XRD analysis in section 6 of the Supporting Information where loss of crystallinity is observed at $400{ }^{\circ} \mathrm{C}$.

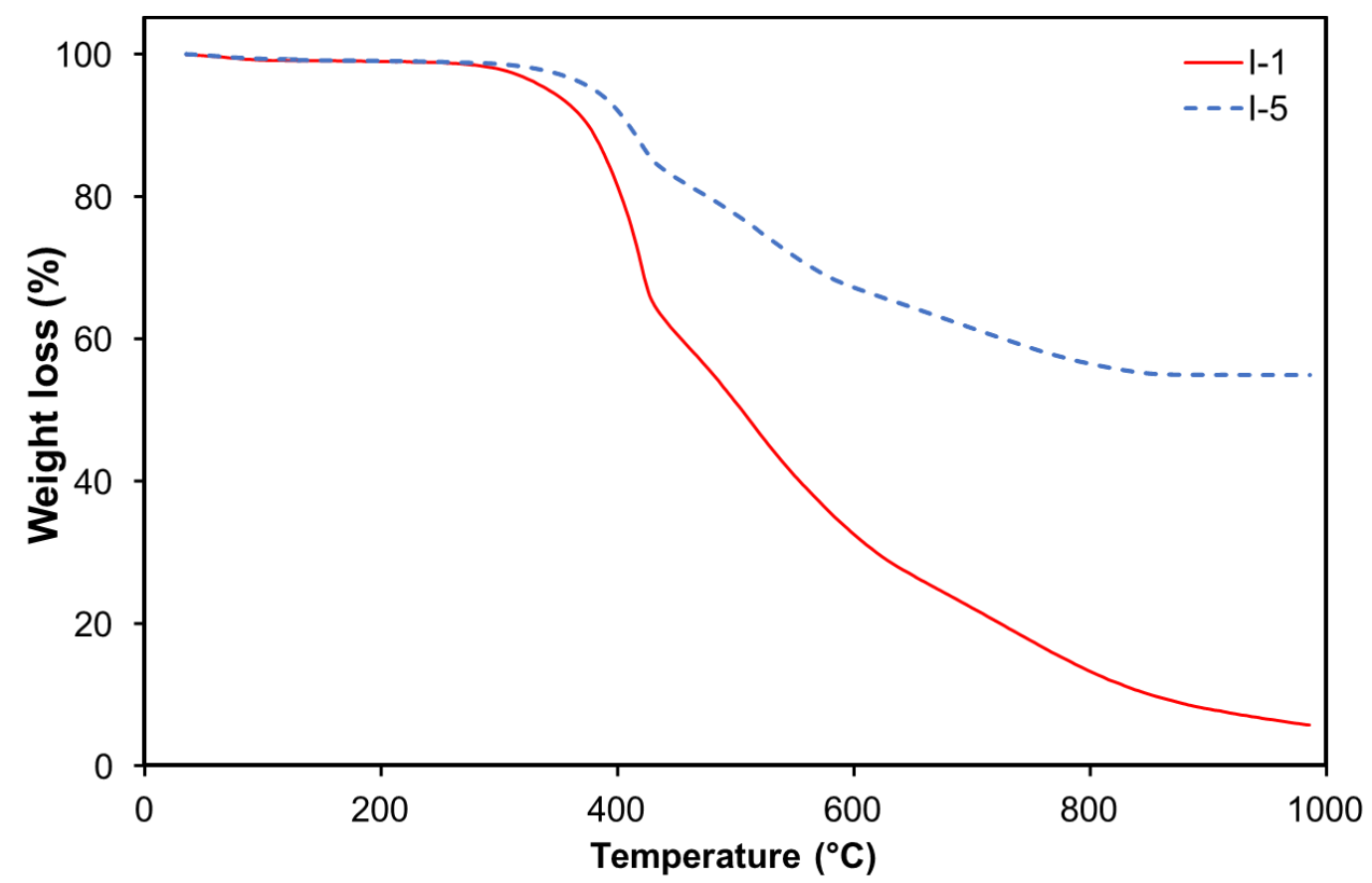

Figure S18: Weight loss of PI powders collected in the bulk solution during preparation of membrane samples. 


\section{Cyclohexane permporometry for pore size determination of the membrane samples.}

A stepwise pore size analysis after each reaction step and comparison with the pristine support was done by employing cyclohexane permporometry and the results are given in Figure S19. The $\gamma$ alumina pristine layer exhibits a relatively narrow pore size distribution with pore diameter of $5.5 \mathrm{~nm}$. After reaction with APTES (sample A) the pore diameter has not been significantly affected and is seemingly similar to the one of the pristine $\gamma$-alumina layer. Further, functionalization with PMDA (B) leads to a significant pore size shrinkage as seen from the oxygen permeance over the partial pressure raw data (Figure 1b). Since there is not an obvious transition point observed at low cyclohexane partial pressures then pore size estimation cannot be done via this method. However, we can safely assume that the pore diameter is $1 \mathrm{~nm}$ or lower due to the limit of the measurement being associated with the molecular diameter of cyclohexane which is $0.5 \mathrm{~nm}$.

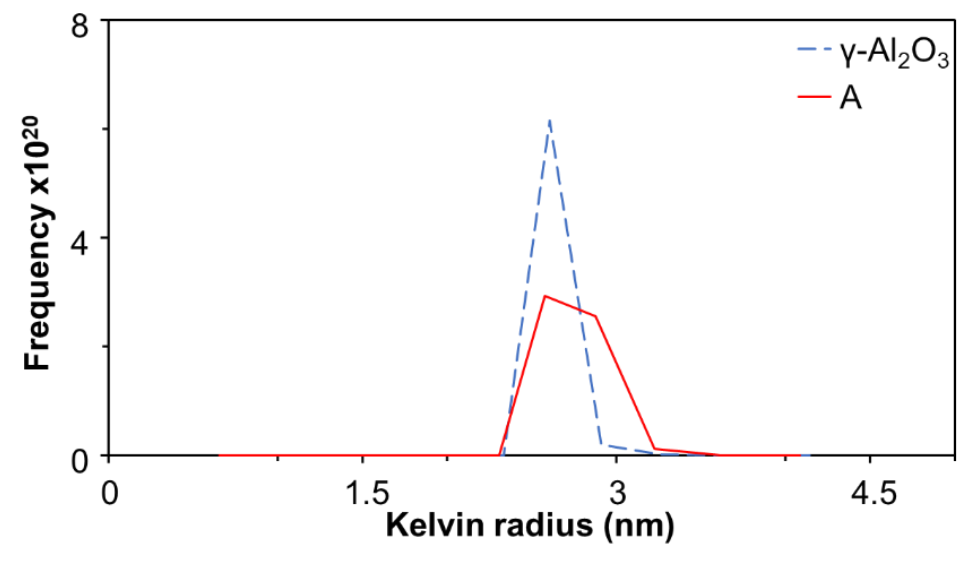

Figure S19: Pore radius distribution of the pristine $\gamma$-alumina layer and a $\gamma$-alumina layer after prefunctionalization with APTES by CVD (A). Values, calculated using the Kelvin equation.

\section{Scanning electron microscopy (SEM).}
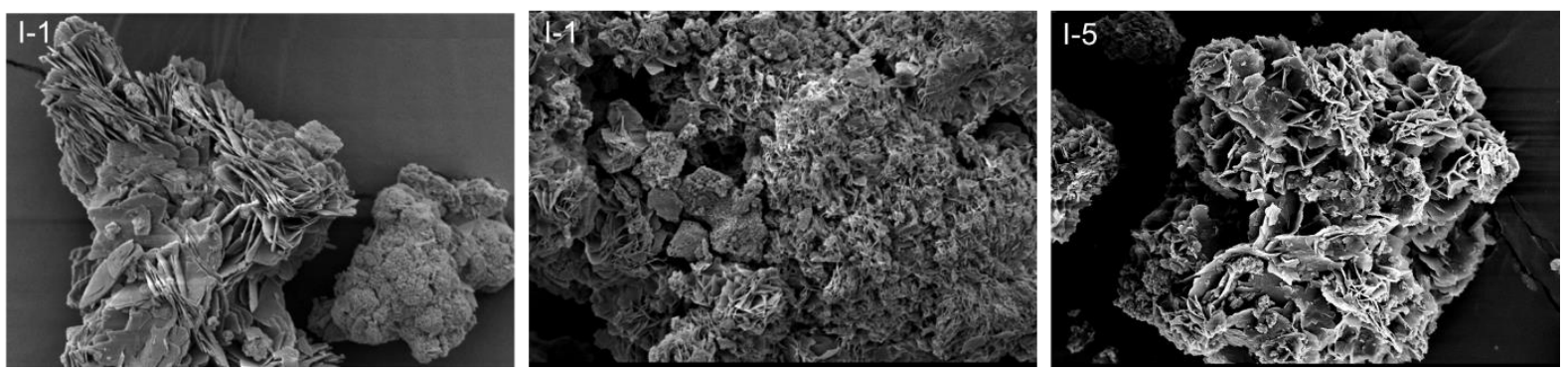

Figure S20: SEM Micrographs of the PI powders prepared for 1 (I-1) or 5 days (I-5). 


\section{High resolution scanning electron microscope (HR-SEM) analysis.}

At the top (Figure S21) the image of a pristine $\alpha$-alumina supported $\gamma$-alumina layer. At the bottom (Figure S22) the top surface and cross-section micrographs of the pristine supported $\gamma$-alumina layer. On the cross-section micrograph the top layer is $\gamma$-alumina and the bottom layer is $\alpha$-alumina.

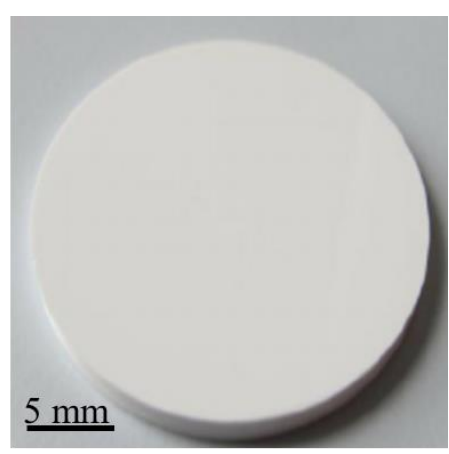

Figure S21: Photograph of the pristine support.
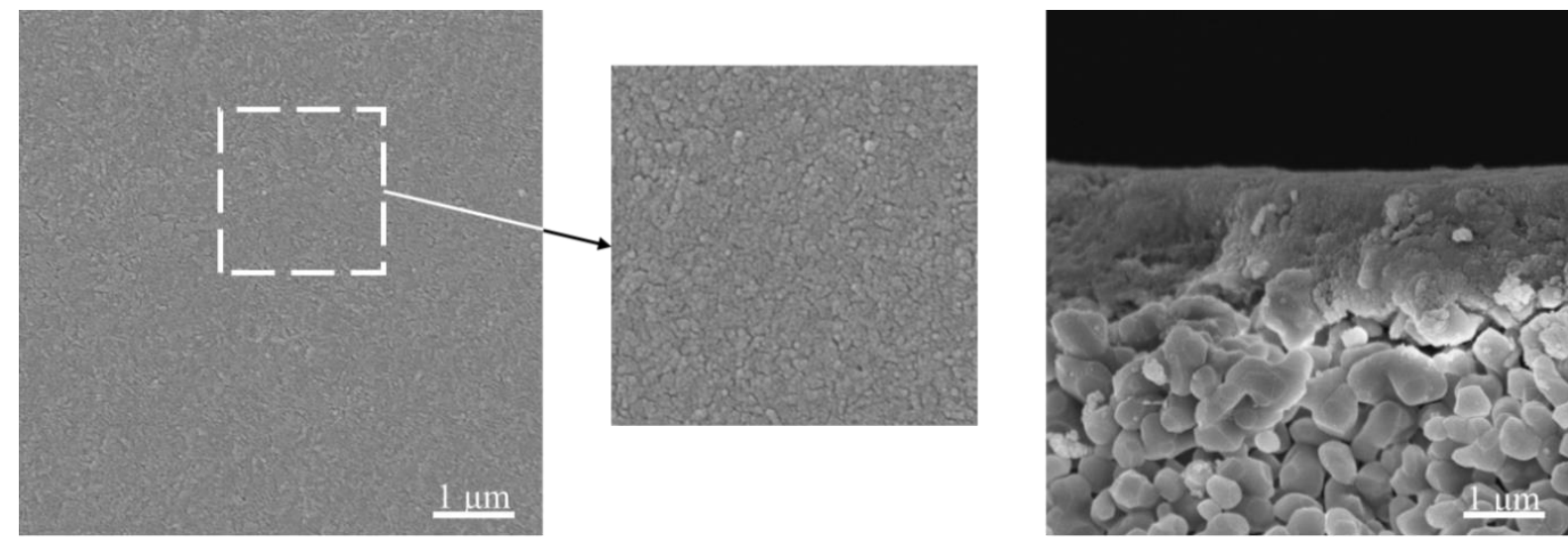

Figure S22: HR-SEM micrograph of the top surface (left and middle) and the cross-section of the pristine support. 


\section{Energy-dispersive X-ray spectroscopy (SEM-EDS).}

The SEM-EDS analysis was done by acquiring a well focused image with secondary electron emission. Then, the backscattered electron (BEC) receiver was switched on and the image(s) (Figure $\mathrm{S} 23 \mathrm{~A}-\mathrm{S} 26 \mathrm{~A}$ ) was focused as best as possible at the magnification of $16 \mathrm{k}$. Then, elemental analysis was done by a point analysis where three points across the cross-section of the membrane were taken in different depths (Table S1 - S3). Each point was measured for 300s in order to acquire an accurate measurement. For each set of points the three data points were averaged and used for the calculation of the carbon to aluminium ratio $(\mathrm{C} / \mathrm{Al})$ which were used in Figure 3. After the elemental analysis was completed the SEM image (Figure S23B - S26B) was recorded at the same spot as where the EDS analysis was performed, by only switching the secondary electron receiver on and focusing the image. A broken line, shown on SEM and BEC micrographs, separates the $\gamma$-alumina from the $\alpha$-alumina layer. The $\gamma$-alumina layer, fully shown micrographs, has a thickness of $1.5 \mu \mathrm{m}$, whereas the $\alpha$ alumina, partially shown, has a thickness of $2 \mathrm{~mm}$.

A-1 sample analysis:
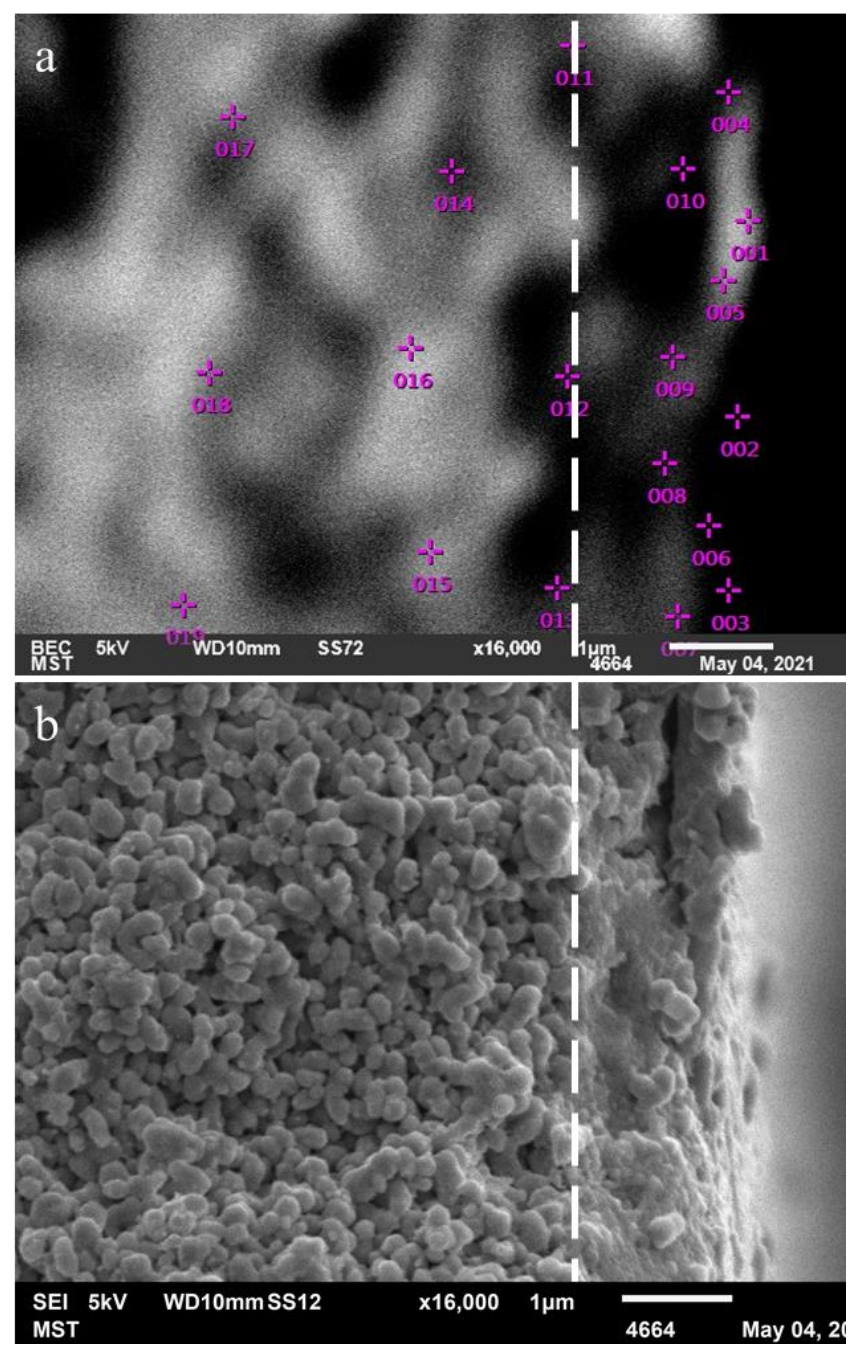

Figure S23: Cross-section micrographs of the same spot of a A-1 sample by using backscattered electrons analysis (a) and secondary electron analysis (b). For the elemental analysis as function of penetration depth, a point analysis was used, where three points were measured across the crosssection at different penetration depths. The white broken line denotes the limit between $\alpha$-alumina (left) and $\gamma$-alumina (right). 
Table S1: Raw data of the point analysis performed on a cross-section of A-1 sample. The points in the table correspond to the pink numbers on the micrograph in Figure S23a.

\begin{tabular}{|c|c|c|c|c|c|c|}
\hline \multirow{2}{*}{ Point } & \multicolumn{4}{|c|}{ Element (mass \%) } & \multirow{2}{*}{$\begin{array}{l}\text { C/Al } \\
\text { ratio }\end{array}$} & \multirow{2}{*}{$\begin{array}{c}\text { Distance from } \\
\text { top surface } \\
(\mu \mathrm{m})\end{array}$} \\
\hline & $\mathbf{C}$ & $\mathbf{N}$ & $\mathbf{O}$ & Al & & \\
\hline 1 & 49 & n.d. & 24 & 27 & 1.8 & \multirow{3}{*}{0.1} \\
\hline 2 & 55 & n.d. & 12 & 33 & 1.6 & \\
\hline 3 & 46 & n.d. & 19 & 35 & 1.3 & \\
\hline 4 & 24 & n.d. & 16 & 60 & 0.4 & \multirow{3}{*}{0.3} \\
\hline 5 & 74 & n.d. & 17 & 9 & 8.6 & \\
\hline 6 & 42 & n.d. & 19 & 39 & 1.1 & \\
\hline 7 & 48 & n.d. & 23 & 29 & 1.6 & \multirow{4}{*}{0.7} \\
\hline 8 & 28 & n.d. & 19 & 53 & 0.5 & \\
\hline 9 & 53 & n.d. & 19 & 28 & 1.9 & \\
\hline 10 & 50 & n.d. & 11 & 39 & 1.3 & \\
\hline 11 & 20 & n.d. & 13 & 67 & 0.3 & \multirow{3}{*}{1.8} \\
\hline 12 & 28 & n.d. & 19 & 53 & 0.5 & \\
\hline 13 & 38 & n.d. & 26 & 35 & 1.1 & \\
\hline 14 & 10 & n.d. & 34 & 55 & 0.2 & \multirow{3}{*}{3.2} \\
\hline 15 & 15 & n.d. & 37 & 48 & 0.3 & \\
\hline 16 & 21 & n.d. & 33 & 46 & 0.5 & \\
\hline 17 & 10 & n.d. & 27 & 63 & 0.2 & \multirow{3}{*}{5.2} \\
\hline 18 & 15 & n.d. & 32 & 53 & 0.3 & \\
\hline 19 & 21 & n.d. & 35 & 43 & 0.5 & \\
\hline
\end{tabular}


B-1 sample analysis:
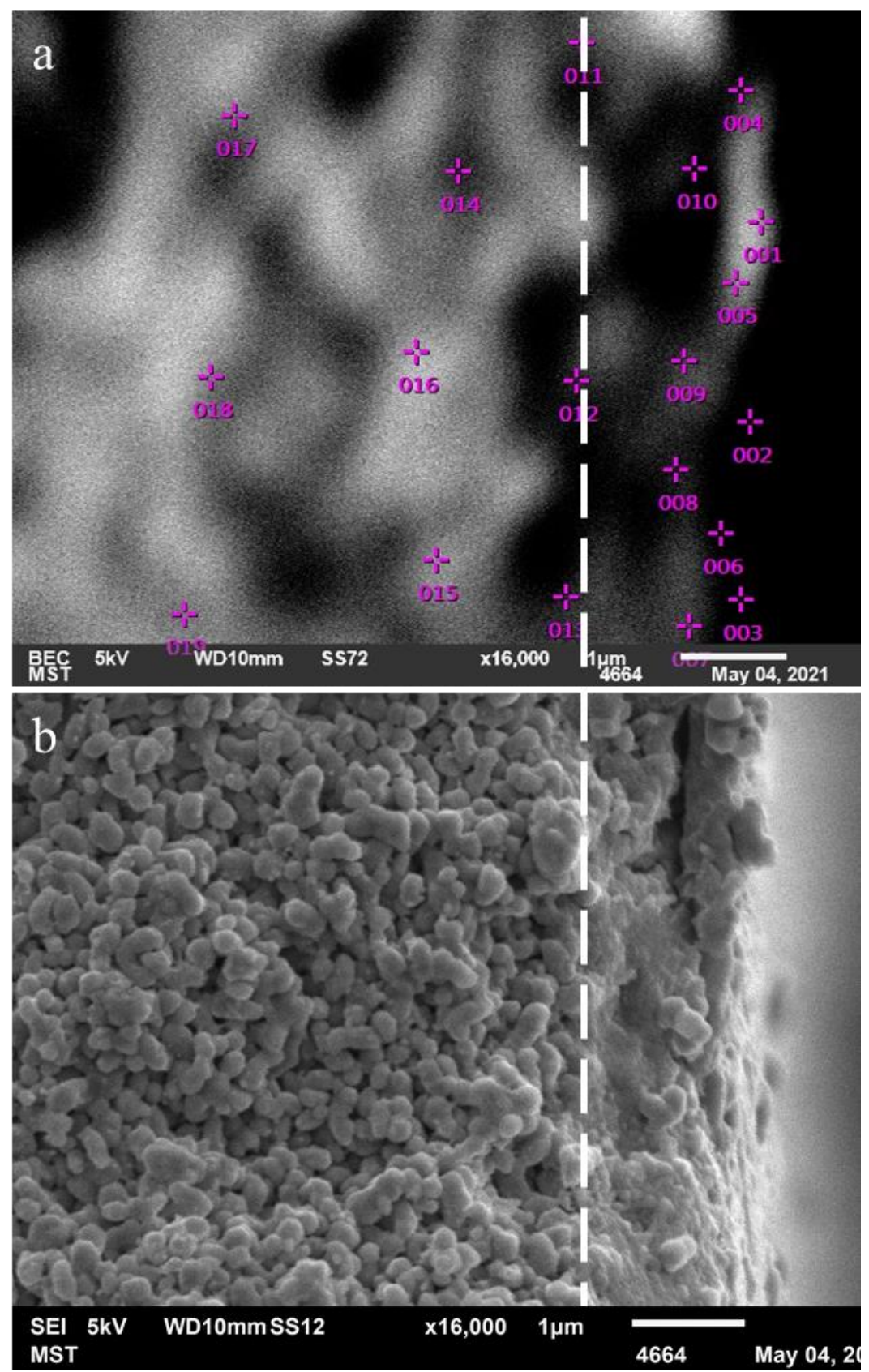

Figure S24: Cross-section micrographs of the same spot of a B-1 sample by using backscattered electrons analysis (a) and secondary electron analysis (b). For the elemental analysis as function of penetration depth, a point analysis was used, where three points were measured across the crosssection at different penetration depths. The white broken line denotes the limit between $\alpha$-alumina (left) and $\gamma$-alumina (right). 
Table S2: Raw data of the point analysis performed on a cross-section of B-1 sample. The points in the table correspond to the pink numbers on the micrograph in Figure S24a.

\begin{tabular}{|c|c|c|c|c|c|c|}
\hline \multirow{2}{*}{ Point } & \multicolumn{4}{|c|}{ Elements (\% mass) } & \multirow{2}{*}{$\begin{array}{l}\text { C/Al } \\
\text { ratio }\end{array}$} & \multirow{2}{*}{$\begin{array}{c}\text { Distance } \\
\text { from top } \\
\text { surface }(\mu \mathrm{m})\end{array}$} \\
\hline & $\mathbf{C}$ & $\mathbf{N}$ & $\mathbf{O}$ & Al & & \\
\hline 1 & 26 & 1 & 37 & 37 & 0.7 & \\
\hline 2 & 20 & 1 & 37 & 43 & 0.5 & 0.3 \\
\hline 3 & 22 & 1 & 38 & 39 & 0.6 & \\
\hline 4 & 22 & 1 & 34 & 43 & 0.5 & \\
\hline 5 & 25 & 1 & 33 & 41 & 0.6 & 0.6 \\
\hline 6 & 21 & 1 & 36 & 42 & 0.5 & \\
\hline 7 & 28 & 1 & 33 & 38 & 0.7 & \\
\hline 8 & 23 & 0 & 34 & 43 & 0.5 & 0.9 \\
\hline 9 & 26 & 1 & 31 & 42 & 0.6 & \\
\hline 10 & 38 & 1 & 28 & 33 & 1.1 & \\
\hline 11 & 46 & nd & 26 & 28 & 1.6 & 1.4 \\
\hline 12 & 15 & 0 & 39 & 46 & 0.3 & \\
\hline 13 & 10 & nd & 33 & 57 & 0.2 & \\
\hline 14 & 11 & 0 & 40 & 50 & 0.2 & 3.2 \\
\hline 15 & 6 & nd & 36 & 57 & 0.1 & \\
\hline 16 & 6 & 0 & 32 & 61 & 0.1 & \\
\hline 17 & 26 & 1 & 37 & 37 & 0.7 & 5.3 \\
\hline 18 & 20 & 1 & 37 & 43 & 0.5 & \\
\hline
\end{tabular}


A-5 sample analysis:
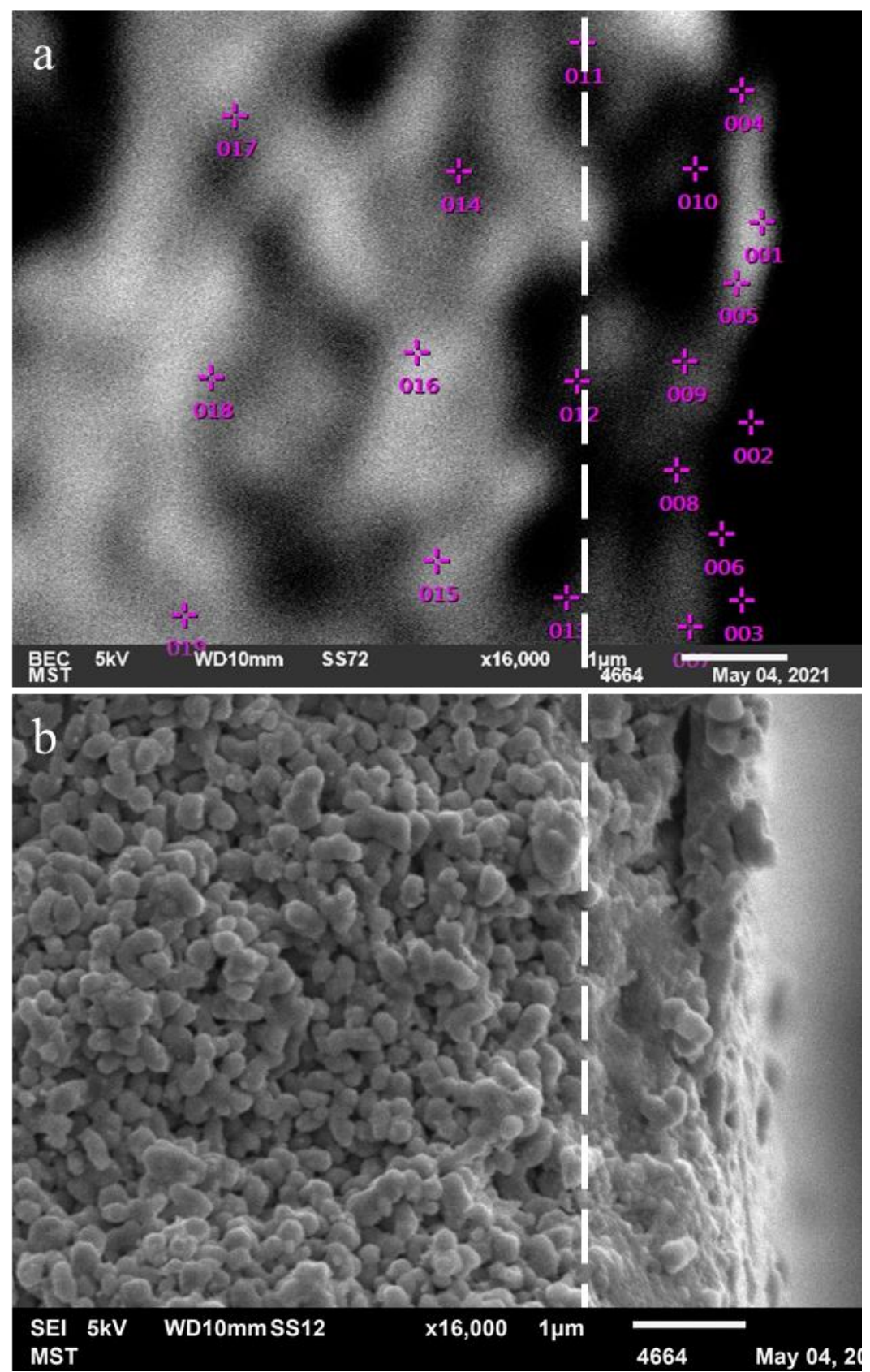

Figure S25: Cross-section micrographs of the same spot of a A-5 sample by using backscattered electrons analysis (a) and secondary electron analysis (b). For the elemental analysis as function of penetration depth, a point analysis was used, where three points were measured across the crosssection at different penetration depths. The white broken line denotes the limit between $\alpha$-alumina (left) and $\gamma$-alumina (right). 
Table S3: Raw data of the point analysis performed on a cross-section of A-5 sample. The points in the table correspond to the pink numbers on the micrograph in Figure S25a.

\begin{tabular}{|c|c|c|c|c|c|c|}
\hline \multirow{2}{*}{ Point } & \multicolumn{4}{|c|}{ Elements (\% mass) } & \multirow{2}{*}{$\begin{array}{l}\text { C/Al } \\
\text { ratio }\end{array}$} & \multirow{2}{*}{$\begin{array}{c}\text { Distance from } \\
\text { top surface } \\
(\mu \mathrm{m}) \\
\end{array}$} \\
\hline & $\mathrm{C}$ & $\mathbf{N}$ & $\mathbf{O}$ & Al & & \\
\hline 1 & 77 & n.d. & 19 & 5 & 15.9 & \\
\hline 2 & 75 & n.d. & 17 & 8 & 9.3 & 0.1 \\
\hline 3 & 68 & n.d. & 14 & 18 & 3.9 & \\
\hline 4 & 75 & n.d. & 18 & 8 & 9.8 & \\
\hline 5 & 69 & n.d. & 14 & 17 & 4.1 & 0.5 \\
\hline 6 & 64 & n.d. & 12 & 24 & 2.7 & \\
\hline 7 & 47 & n.d. & 7 & 46 & 1.0 & \\
\hline 8 & 55 & n.d. & 9 & 36 & 1.5 & 0.8 \\
\hline 9 & 66 & n.d. & 12 & 21 & 3.1 & \\
\hline 10 & 15 & n.d. & 29 & 55 & 0.3 & \\
\hline 11 & 18 & n.d. & 6 & 77 & 0.2 & 2.2 \\
\hline 12 & 13 & n.d. & 6 & 81 & 0.2 & \\
\hline 13 & 19 & n.d. & 35 & 46 & 0.4 & \\
\hline 14 & 16 & n.d. & 28 & 56 & 0.3 & 4.1 \\
\hline 15 & 12 & n.d. & 36 & 52 & 0.2 & \\
\hline 16 & 12 & n.d. & 36 & 51 & 0.2 & \\
\hline 17 & 21 & n.d. & 28 & 50 & 0.4 & 5.5 \\
\hline 18 & 25 & n.d. & 27 & 48 & 0.5 & \\
\hline
\end{tabular}


B-5 sample analysis:

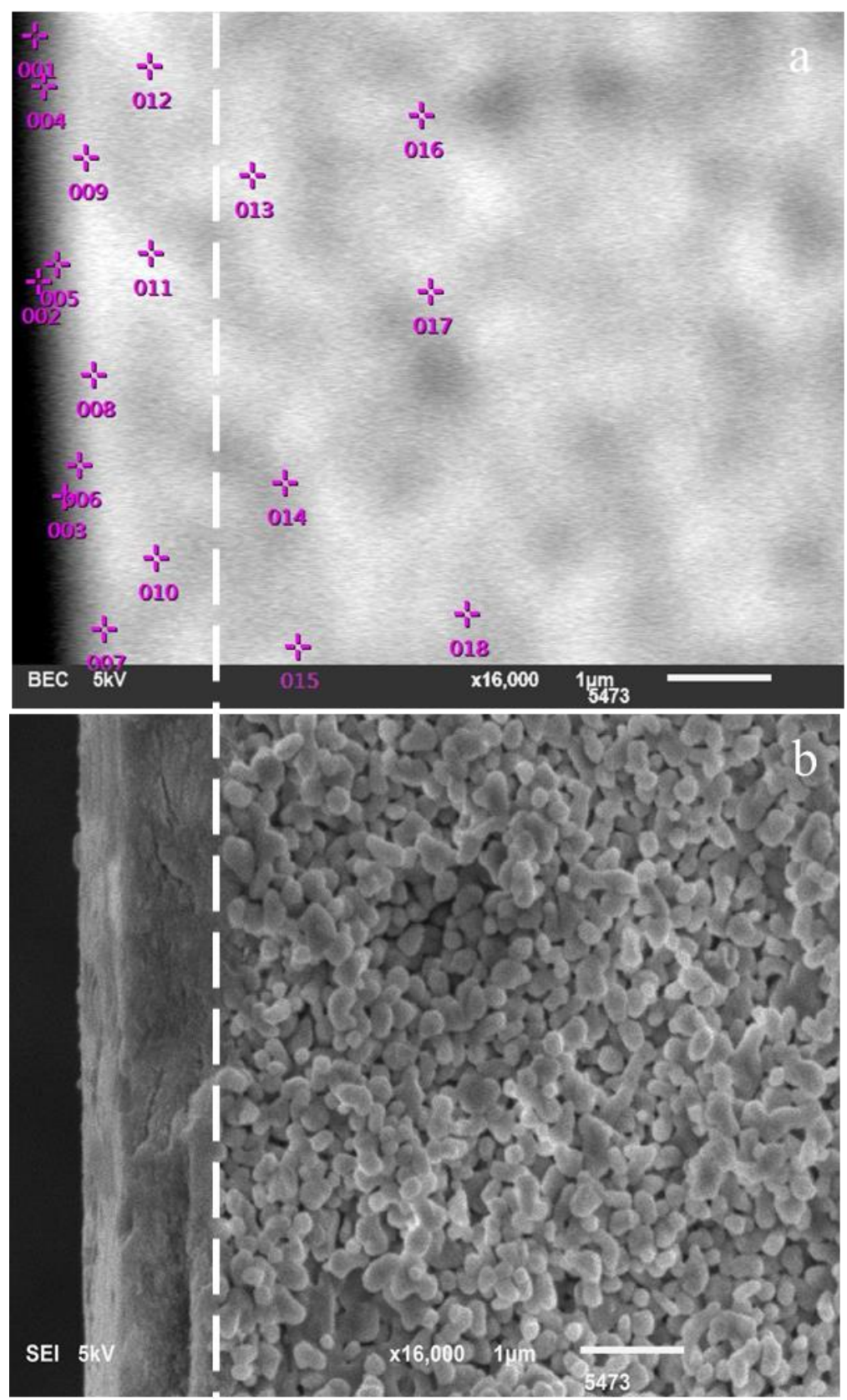

Figure S26: Cross-section micrographs of the same spot of a B-5 sample by using backscattered electrons analysis (a) and secondary electron analysis (b). For the elemental analysis as function of penetration depth, a point analysis was used, where three points were measured across the cross-section at different penetration depths. The white broken line denotes the limit between $\alpha$-alumina (right) and $\gamma$-alumina (left). 
Table S4: Raw data of the point analysis performed on a cross-section of A-5 sample. The points in the table correspond to the pink numbers on the micrograph in Figure S26a.

\begin{tabular}{ccccccc}
\hline \multicolumn{6}{c}{ Elements (\% mass) } & \multicolumn{2}{c}{$\begin{array}{c}\text { Distance from } \\
\text { Point }\end{array}$} & C & N & O & Al & ratio & $(\boldsymbol{\mu m})$ \\
\hline 1 & 37 & 1 & 22 & 40 & 1 & \\
2 & 46 & 1 & 20 & 33 & 2 & 0.1 \\
3 & 39 & 1 & 23 & 36 & 3 & \\
\hline 4 & 42 & 1 & 19 & 38 & 4 & \\
5 & 46 & 1 & 20 & 34 & 5 & 0.3 \\
6 & 46 & 1 & 20 & 34 & 6 & \\
\hline 7 & 37 & 2 & 28 & 34 & 7 & \\
8 & 35 & 1 & 25 & 39 & 8 & 0.6 \\
9 & 32 & 1 & 27 & 40 & 9 & \\
\hline 10 & 14 & 1 & 38 & 47 & 10 & \\
11 & 13 & 1 & 38 & 49 & 11 & 1.2 \\
12 & 15 & 1 & 33 & 51 & 12 & \\
\hline 13 & 8 & 1 & 35 & 56 & 13 & \\
14 & 7 & 1 & 36 & 56 & 14 & 2.3 \\
15 & 7 & 1 & 41 & 51 & 15 & \\
\hline 16 & 8 & 0 & 40 & 52 & 16 & \\
17 & 10 & 1 & 37 & 52 & 17 & 3.9 \\
18 & 6 & 1 & 40 & 54 & 18 & \\
\hline & & & & & \\
\hline
\end{tabular}

\section{Long-term stability of A-5 membrane sample.}

Sample A-5 was tested in aqueous solution of Rhodamine B for 5 days where the retention and water flux was monitored. The results show that the membrane's performance was stable after 5 days of testing.

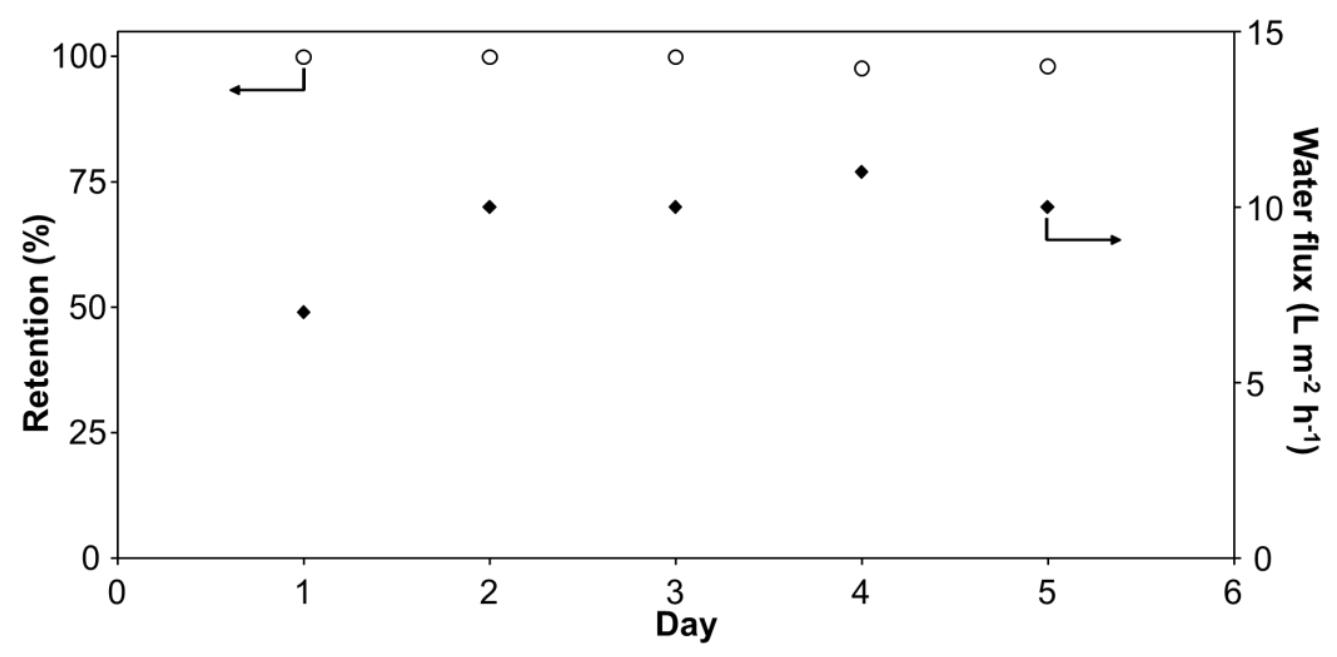

Figure S27: Stability of sample A-5 in aqueous solution of RB under applied pressure of 11 bars. 


\section{References.}

(1) Liu, C.; Shih, K.; Gao, Y.; Li, F.; Wei, L. Dechlorinating Transformation of Propachlor through Nucleophilic Substitution by Dithionite on the Surface of Alumina. J. Soils Sediments 2012, 12 (5), 724-733. https://doi.org/10.1007/s11368-012-0506-0.

(2) Costa, T. M. H.; Gallas, M. R.; Benvenutti, E. V; Da Jornada, J. A. H. Study of Nanocrystalline $\gamma$-Al2O3 Produced by High-Pressure Compaction. J. Phys. Chem. B 1999, 103, 4278-4284. https://doi.org/10.1021/jp983791o.

(3) Bistričić, L.; Volovšek, V.; Dananić, V. Conformational and Vibrational Analysis of GammaAminopropyltriethoxysilane. J. Mol. Struct. 2007, 834-836, 355-363.

https://doi.org/10.1016/j.molstruc.2006.10.036.

(4) Zhang, Y.; Zhang, M.-S.; Zhang, Y.; Chen, X.-W.; Wang, J.-H. Green and Catalyst-Free Preparation of Triazinyl Polyimide for the Efficient Adsorption of Glycoproteins. RSC Adv. 2016, 6, 46002-46007. https://doi.org/10.1039/c6ra05411k.

(5) Yan, W.; Yuan, P.; Chen, M.; Wang, L.; Liu, D. Infrared Spectroscopic Evidence of a Direct Addition Reaction between Palygorskite and Pyromellitic Dianhydride. Appl. Surf. Sci. 2013, 265, 585-590. https://doi.org/10.1016/j.apsusc.2012.11.051.

(6) Wang, T.; Xue, R.; Chen, H.; Shi, P.; Lei, X.; Wei, Y.; Guo, H.; Yang, W. Preparation of Two New Polyimide Bond Linked Porous Covalent Organic Frameworks and Their Fluorescence Sensing Application for Sensitive and Selective Determination of Fe ${ }^{3+}$. New J. Chem. 2017, 41 (23), 14272-14278. https://doi.org/10.1039/C7NJ02134H.

(7) Li, Z.; Zhou, J.; Xu, R.; Liu, S.; Wang, Y.; Li, P.; Wu, W.; Wu, M. Synthesis of Three Dimensional Extended Conjugated Polyimide and Application as Sodium-Ion Battery Anode. Chem. Eng. J. 2016, 287, 516-522. https://doi.org/10.1016/j.cej.2015.11.063.

(8) Fang, Q.; Zhuang, Z.; Gu, S.; Kaspar, R. B.; Zheng, J.; Wang, J.; Qiu, S.; Yan, Y. Designed Synthesis of Large-Pore Crystalline Polyimide Covalent Organic Frameworks. Nat. Commun. 2014, 5 (1), 4503. https://doi.org/10.1038/ncomms5503.

(9) Wang, Y.; Gao, Q.; You, Q.; Liao, G.; Xia, H.; Wang, D. Porous Polyimide Framework: A Novel Versatile Adsorbent for Highly Efficient Removals of Azo Dye and Antibiotic. React. Funct. Polym. 2016, 103, 9-16. https://doi.org/10.1016/J.REACTFUNCTPOLYM.2016.04.004.

(10) Sadhasivam, B.; Muthusamy, S. Synthesis and Characterization of Optically Active Polyimides and Their Octa(Aminophenyl)Silsesquioxane Nanocomposites. High Perform. Polym. 2016, 28 (5), 547-561. https://doi.org/10.1177/0954008315591021.

(11) Taublaender, M. J.; Reiter, M.; Unterlass, M. M. Highly Crystalline, Nanostructured Polyimide Microparticles via Green and Tunable Solvothermal Polymerization. Macromolecules 2019, 52 (16), 6318-6329. https://doi.org/10.1021/acs.macromol.9b00985. 